Recibido 05 de Mayo, 2019 - Aceptado 05 de Junio, 2019

\title{
La clase insecta en la Iconografía Inka
}

\section{The insecta class in the Inka Iconography}

\author{
Efrain Suclli, Melanie Moriano, Jaime Deza ${ }^{3}$
}

\section{RESUMEN}

El presente trabajo permite establecer niveles de interacción respecto a la percepción de los insectos frente a las actividades humanas, estas fueron plasmadas en gráficas recogidas por el investigador Jenaro Fernández Baca Cosio el año 1980, igualmente se recogió información de etnográfica y el registro de motivos de cerámica expuestas en el museo de la Casa Concha, entre otros.

Los gráficos estilizados representarían a un total de 21 especímenes de insectos representados en Iconografía Inka, ubicados en 7 órdenes, 12 familias y 9 géneros, todo ellos expresarían un lenguaje abstracto sobre la vinculación antrópica y una respuesta cultural sobre el efecto de los insectos y los cultivos en forma de plagas, polinizadores, predadores de otros insectos, y sobre todo la fascinación que despertaron en el quehacer humano.

Palabra clave: Insectos, iconografía Inka, vinculación antrópica

\section{ABSTRACT}

The present work allows to establish levels of interaction regarding the perception of insects against human activities, these were reflected in graphs collected by the researcher Jenaro Fernández Baca Cosio in 1980, ethnographic information and the registration of reasons for pottery exhibited in the Casa Concha museum, among others.

The stylized graphics would represent a total of 21 insect specimens represented in Inka Iconography, located in 7 orders, 12 families and 9 genera, all of which would express an abstract language about anthropic bonding and a cultural response on the effect of insects and animals. crops in the form of pests, pollinators, predators of other insects, and especially the fascination that awoke in human activity.

Keyword: Insects, Inka iconography, anthropic bonding

1. Biólogo egresado de la UNSAAC - Cusco Perú. Email: Efrain_sms@hotmail.com

2. Biólogo egresado de la UNSAAC - Cusco Perú Email: Melanice20@gmail.com

3. Antropólogo. Universidad Alas Peruanas. Lima Email: Jaimedeza_@hotmail.com 


\section{INTRODUCCIÓN}

El presente tratado, nos permite establecer niveles de interacción de actividades humanas y el entorno biótico, esto, a partir de las relaciones establecidas entre la dinámica ecológica de los insectos y el hombre; es así, por ejemplo, que muchas de las actividades que atañen a la cadena productiva agrícola fue plasmada gráficamente en la cerámica Inka, expresado en una forma de lenguaje simbólico abstracto sobre el quehacer humano.

Los estudios desarrollados sobre iconografía Inka, en general, demuestran una estrecha vinculación y asociación con elementos del medio natural y cultural. Por otro lado, las fuerzas naturales como el clima, movimientos de masas de aire, tectónica de suelos, entre otros, acontecen directamente sobre la biología de muchas especies de animales, como los insectos y estos a su vez sobre las actividades humanas, incidentalmente la proliferación de varias especies hasta los niveles de plagas son muy comunes en regiones neo-tropicales de los Andes, como es el caso del región andina.

Es así, que a partir del establecimiento de sinergias entre varios tipos insectos y cultivares prehispánicos como el "maíz", "ajíes" y/o "rocotos" se logró registrar siete tipos de insectos pertenecientes a los órdenes Coleóptera, Dermáptera y Díptera, la mayoría tipificados como plagas y en la forma de predadores naturales. Los motivos estilizados más recurrentes corresponden a mariposas (Lepidópteros), hormigas (Himenópteros) y mosquitos (Dípteros); todas ellas, representarían a la entomofauna local, objeto de ponderación por el realismo de su representación.

En general, los insectos pertenecen al grupo de animales invertebrados de estructura articulada conocidos como artrópodos, taxonómicamente ubicados en la Clase Insecta, cuya evolución tiene una datación aproximada de 350 millones de años comparados con los dos 2.5 millones de años de evolución humana. El enorme éxito que tuvieron como habitantes de la tierra se debe al potencial reproductivo, capacidad de sobrevivencia a diferentes hábitats, diversidad y tamaño (Ortega 1987: 1); estos ocupan casi todos los espacios ecológicos, en muchos casos determinando positiva y negativamente actividades de subsistencia humana.

\section{Etnohistoria de los insectos}

Son varios los trabajos que hacen referencia a la ecología y biología de insectos en general. En contraste son pocos los estudios que abordan aspectos etnobiológicos, sobre todo los que guardan relación con éste particular grupo de animales invertebrados. Sin embargo, destacan algunas publicaciones del siglo pasado, que tratan de aspectos arqueológicos e históricos, fotografías y dibujos de muestras de cerámica, donde se aprecian representaciones de insectos (Bingham 1970, Fernández Baca 1971, Del Busto 1988, Lumbreras 1969, Vidal 1958).

El cronista mestizo, Inca Garcilaso de la Vega (1991 [1960]) señala que, en las casas reales de Cusco, existían jardines en los que se apreciaban representaciones de plantas y animales hechos de oro y plata, en tamaño natural. Entre los animales menciona a roedores, lagartijas, mariposas, zorros y otros.

En los estudios desarrollados por Rafael Larco en 1938, destaca una vasija, entre las piezas de cerámica de la cultura Moche, en cuyo cuerpo globular resalta la figura de un insecto acuático de la familia Belostomatidae (Hemíptera), y en el cuello de ésta, se encuentra el modelado del "pato criollo" Cairiana moschata (Anatidae). Esta relación con el ave podría inferir una posible relación alimenticia.

En los apuntes de Antonio Raymondi (1940: 39) sobre los valles bajos y calurosos del Cusco, menciona la gran proliferación de insectos en las vivencias, principalmente cucarachas. Esta circunstancia denota una presión ambiental por parte de éstos. 
El investigador cusqueño Jenaro Fernández B. en sus obras Motivos de la ornamentación de la cerámica Inka Cusco, 1971, tomos I y II, éste último auspiciado por el CONCYTEC; y La pintura Inka en cerámica, editado el año 1980 por el Instituto Nacional de Cultura, reproduce formas y colores de dibujos zoomorfos y fitomorfos procedentes de fragmentos de cerámica Inka.

El Dr. Gerardo Lamas en el año 1980, al tratar sobre la Historia de la Entomología en el Perú hace referencia a aspectos de la entomología Prehispánica, mencionando a Larco Hoyle (1983), Lavalle (1970), Ravines (1978) y Monge (1973) quienes en sus obras muestran pictografías de insectos en cerámica correspondientes a las culturas Mochica y Pachacamac. También señala la existencia de una hermosa representación de mariposa estilizada en la obra de Hiram Bingham. Menciona, además, "sería muy interesante realizar un análisis más detallado de las muestras arqueológicas que contengan diseños entomológicos".

Del Busto en 1988, muestra en su obra Perú Incaico, una fotografía referida a un magnifico aríbalo inka ornado con figuras de insectos. Hace mención, acerca de los motivos de ornamentación de la cerámica y tejidos, que solían ser figuras geométricas y en ocasiones aves, insectos y plantas.

En el año 1995, el trabajo del Ing. Willy F. Vargas Musquipa, Insectos en la iconografía Inka, publicado en la Revista Peruana de Entomología $N^{\circ}$ 37, informa sobre representaciones (iconografía de insectos) de la cultura Inka. Muestra $18 \mathrm{di}$ seños procedentes de evidencia arqueológica y bibliográfica, desarrolla una descripción desde el punto de vista entomológico.

En el año 1998, Enrique Angulo desarrolla la investigación acerca del proceso de domesticación del "pato criollo" Cairiana moschata (Anatidae) en Sudamérica. Este autor, supone a los insectos como el principal motivo para la incorporación de ésta especie en la esfera doméstica. Los considera como una presión ambiental que recibe una respuesta cultural especifica con el uso humano de esta ave.

Elmo León, en su obra 14000 años de alimentación en el Perú, recopila información sobre especies de insectos utilizados en la dieta humana en la época Precolombina. También hace referencia del valor nutricional producto de la ingesta de éstos (León 2013: 478-479).

Carlos Reynel R, et al. 2007, hace mención a un insecto Lepidóptero cuya larva es consumido tradicionalmente por los pobladores de Calca, en el departamento del Cusco. Este insecto es llamado "huaytampu" Metardaris cosinga (Hesperidae) el cual vive y ataca los brotes tiernos del árbol "chachacomo" Escallonia resinosa Ruiz \& Pavon (Escalloniaceae).

\section{Vinculación antrópica}

Los grupos humanos que poblaron esta región Sudamericana, han manejado un amplio espectro de animales asociados al quehacer humano. Uno de los grupos, al cual hacemos referencia, son los invertebrados incluidos en la Clase Insecta. Estos fueron motivo de observación conductual, reflejados en los diseños iconográficos de la cultura inka. El conocimiento adquirido respecto a la biología de estas especies entomológicas, forma parte de una importante herencia de utilidad práctica y explicativa de interacción humana.

Respecto a sus usos, existe un amplio conocimiento vinculado, especialmente a la culinaria entomológica, desde tiempos pretéritos en América -entomofagia prehispánica- (Dofur \& Sander 2000). Sin embargo, los informes del consumo de insectos en el Perú Prehispánico son escasos. Al respecto, Weir \& Bonavia (1985: 98) identificaron restos quitinosos de un escarabajo (Coleóptero en materia fecal, coprolito) procedentes del sitio PV35-6 en Huarmey, que tiene un fechado de 2450 a.C.

Para los autores, esto no representaría una novedad, ya que se comían insectos en época pre- 
hispánica en el norte de América. Por otro lado, Antúnez de Mayolo (1981) sostiene que larvas, orugas y hormigas, fueron fuente de proteínas y lípidos en la dieta Prehispánica. En el contexto actual se menciona al suri -que es una larva del insecto Coleóptero Rhynchophorus spp. (Curculionidae)-, cuyo consumo está ampliamente distribuido en toda la Amazonía peruana.

En el territorio del Brasil, este insecto es semi-cultivado desde tiempos ancestrales por poblaciones indígenas (Chagnon 1968). Otros autores, como Delgado et al. 2008, afirma, que la larva de suri juega un rol importante como fuente proteica de muchos pueblos indígenas amazónicos.

Las personas colectan las larvas de los troncos caídos, los comen directamente o los llevan a sus casas para asarlos; el aceite es extraído para sazonar la comida y utilizado en la medicina tradicional, como por ejemplo curar bronquitis, el reumatismo, la pulsaría, etc. Además, acota, que hoy en día las larvas preparadas en sus diferentes formas son parte del menú que ofertan lujosos restaurantes en la ciudad de Iquitos y la capital Lima.

En la región andina de nuestro medio, destaca la presencia del "huaytampu", la forma larval del Lepidóptero Metardaris cosinga (Hesperidae) que es consumida en el mes de junio. La preparación de este es tostado y consumido directamente. La forma tostada molida, es usada como ingrediente de la "ocopa", un tipo de crema de ají que acompaña a muchos platos.

Otro carácter importante es su rol como limitantes ambientales, en el proceso de sedentarización humana. Son varios los informes al respecto. Destacan los casos específicos a la presión constante que ejercen los insectos en la vida de los grupos humanos en las tierras bajas del Centro y Sur de América.

Se sostiene la argumentación que considera a los insectos como la variable ecológica que determina una respuesta cultural específica con la incorporación de predadores naturales de estos, como las aves (Chagnon 1968: 25, Baldus 1970: 143, Mimuendaju 1974: 119, Ruddle 1973: 95-96, Gordon 1957: 16-17, Barrett 1925: 18).

$\mathrm{Al}$ respecto, se informa que en la costa norte del país, los pobladores acostumbran mantener en sus casas un ave terrestre que se alimenta de insectos, llamado huerequeque, Burhinus superciliaris (Ortiz 1996).

El procedimiento de asociar esta ave en las viviendas, como controlador de insectos, puede ser anterior a la llegada de los europeos a Sudamérica. En el folklore musical y en particular en una marinera, la composición llamada Huerequeque, de V. Misinaka y A. Montalvo, menciona su función limpiadora, en clara referencia a los insectos domésticos.

De la misma manera la incorporacion de pato domestico o joque Cairina moschata (Anatidae), está vinculado a esta práctica, cuyo origen se evidencia desde el Chaco Guayanay hasta el territorio peruano (Angulo 1998).

Igualmente, en esta región del sureste de Bolivia se describen prácticas que realizaban grupos humanos para combatir las plagas de langostas, especies de alta capacidad reproductiva de las familias Acrididae y Cyrtacanthacridinidae (Hogue 1993: 164-165).

Estos pobladores utilizaban el siguiente procedimiento: cuando los individuos inmaduros de las langostas todavía no alzaban vuelo y permanecían en el suelo, se practicaban surcos largos y profundos en la tierra, a donde eran conducidos. Luego, con la ayuda de mazas de madera se procedía a comprimirlos, para así producir una masa que se usaba como abono, al que consideraban de alta calidad.

También los pobladores de esa zona consumían las langostas tostadas (Olmos 1929: 100-101). Los apuntes de Antonio Raimondi (1940: 39) sobre los valles bajos y calurosos de la region del 
Cusco en el sureste de Perú, mencionan también la gran proliferación de cucarachas en las viviendas de estos pobladores.

\section{MÉTODOS Y MATERIALES}

El estudio de la iconografía Inka y su aproximación a la relación con la Clase Insecta, se concibe a partir del análisis de 30 láminas de iconografía Inka (tabla 1), procedentes en su mayoría de los textos: Motivos de la ornamentación de la cerámica Inka Cusco, Tomos II editada en 1971 y La pintura Inka en cerámica, editada en 1980 por el investigador Jenaro Fernández Baca Cosio y muestras de cerámica exhibidas en el Museo de la Casa Concha en la ciudad del Cusco.

\section{Aproximación Taxonómica}

La aproximación taxonómica, se logra a partir de la observación directa, bibliografía especializada y el apoyo de entomólogos del Laboratorio de Entomología de la UNSAAC y el área de Entomología del Museo de Historia Natural de la UNMSM.

Los usos y atributos conferidos a las especies, fueron discernidos a través de la comunicación personal y analogía etnográfica. Para la captura de microfotografías se utilizó el Microscopio Estereoscópico de 50X. Modelo Nsz-608T del Laboratorio de Entomología de la Facultad de Ciencias Biológicas UNSAAC.

\section{Tabla $N^{\circ} 1$. Lista de figuras, láminas e imágenes utilizadas en el estudio}

$\begin{array}{cccc}\text { ORDEN } & \text { Figuras } & \text { Láminas } & \text { Imágenes } \\ \text { COLEÓPTERA } & 2 & 2 & 2 \\ \text { DERMÁPTERA } & 1 & 1 & 1 \\ \text { DÍPTERA } & 11 & 11 & 3 \\ \text { HYMENOPTERA } & 4 & 3 & 1 \\ \text { MEGALOPTERA } & 1 & 1 & \\ \text { HEMIPTERA } & 1 & 1 & 5 \\ \text { LEPIDOPTERA } & 9 & 11 & \mathbf{1 2} \\ \text { Total } & \mathbf{2 9} & \mathbf{3 0} & \end{array}$

\section{RESULTADOS}

Las aproximaciones en base a los caracteres morfológicos de insectos y su asociación vegetal permitieron determinar un promedio de 21 especímenes de insectos representados en Iconografía Inka.

Estos están ubicados en 7 órdenes, 12 familias y 9 géneros (tabla 2). Se identificó la asociación de 7 especies de insectos correspondientes a los órdenes Diptera, Coleoptera y Dermaptera con los cultivos de Zea mays L. "maíz" y Capsicum spp. "ajî", "rocoto", infiriéndose un posible vínculo relacional como determinantes ambientales desde el periodo Horizonte Tardío.

A partir del ensayo experimental del cultivo de "maíz" en andenes de factura Inka, sito en el sector de Choqesuysuy Km. 106, Machu Picchu.

Se reporta la presencia de insectos probablemente vinculados a éste. Se diagramaron un total 29 figuras de insectos estilizados para complementar las labores de reconocimiento e interpretación. 
Tabla N² 2. Ubicación taxonómica de insectos estudiados

\begin{tabular}{|c|c|c|c|c|}
\hline ORDEN & Familia & Género & Especies & Total \\
\hline \multirow{2}{*}{ COLEOPTERA } & Curculionidae & Pagiocerus & 1 & \multirow{2}{*}{2} \\
\hline & Meloidae & Pseudomeloe & 1 & \\
\hline \multirow[t]{2}{*}{ DERMAPTERA } & Formiculidae/Labiduridae & & 1 & 1 \\
\hline & Tephritidae & & 2 & \multirow{5}{*}{10} \\
\hline \multirow{4}{*}{ DÍPTERA } & & & 2 moscas & \\
\hline & & & 1 mosquito - zancudo & \\
\hline & Tipulidae & & 2 & \\
\hline & Culicidae & & 3 mosquitos hematófagos & \\
\hline HYMENÓPTERA & Formicidae & Camponotus & 2 & 2 \\
\hline MEGALÓPTERA & Corydalidae & Corydalus & 1 & 1 \\
\hline HEMÍPTERA & Pentatomidae & & 1 & 1 \\
\hline \multirow{4}{*}{ LEPIDOPTERA } & Nymphalidae & Caligo & 1 & 1 \\
\hline & Hesperidae & Metardis & 1 & 1 \\
\hline & & Heliopetes & 1 & 1 \\
\hline & Sphingidae & Euryglottis/Tyrsonia & 1 & 1 \\
\hline \multicolumn{4}{|c|}{ TOTAL } & 21 \\
\hline
\end{tabular}

\section{REFERENCIAS CITADAS:}

Angulo E. (1998). Interpretación biológica acerca de la domesticación del pato criollo Cairina moschata. Instituto Francés de Estudio Andinos 27(1), pp. 17-40.

Antúnez de Mayolo S. (1981). La nutrición en el Antiguo Perú. Lima: Banco Central de Reserva del Perú.

Baldus H. (1970). Tapirapé tribo Tupino Brasil Central, pp. 510. Sao Paulo: Companhia Editora Nacional.

Barrett S. (1925). The Cayapa Indians of Ecuador. Indian Notes and Monographs, parte 1(40), pp. 181. Museum of the American Indian, Heye Fundation.

Bingham H. (1970). Machupicchu, la ciudad perdida de los Incas, pp. 374. Santiago de Chile: Editora Zig-Zag.

Chagnon N. (1968). Yanomano: the Fierce People, pp. 142. New York: Holt. Rinchart and Winston.

Del Busto D. J. (1988). Perú Incaico. Lima: Librería Studium S.A.

Dofur D \& Sander J. (2000). Insects, En: The Cambrigde World History of Food. Vol. 1.

Fernández Baca J. (1971). Motivos de ornamentación de la cerámica inca. Tomo II. CONCYTEC / INC Cusco Perú.

1980 La pintura Inka en cerámica, editada por el INC Cusco.
Garcilaso de la Vega I. (1991 [1960]), Comentarios reales de los incas, T. II, pp. 465. Lima: Fondo de Cultura Económica.

Gordon B. (1957). Human Geography and Ecology in the Sinu Country of Colombia, pp. 130. Berkeley Ca: University of California Press.

Hogue C. (1993). Latin American Insects and Entomology, pp. 536. Berkeley University of California Press.

Larco Hoyle R. (1938). Los Mochicas, Tomo I, pp. 139. Lima: La Crónica y Variedades.

Lamas G. (2004). Las Mariposas de Machu Picchu. PROFONANPE. Primera edición. Lima: Impreso por BIBLOS.

Lavalle D. (1970). Les representations animales dans la céramique Mochica. Memories De L'Institut Francais D'Étnologie, IV : pp. 210. Paris.

León E. (2013). 14000 años de alimentación en el Perú. Lima: Fondo editorial Universidad San Martin de Porres.

Lumbreras L. G. (1969). Perú Antiguo. Lima

Mimuendaju C. (1974). Farming Among the Eastem Timbira. In: Native South Americans Erhnology of the Least Known Continent. Boston Toronto: Little, Brown and Comapany.

Olmos L. (1929). El Chaco, pp. 154. La Paz: Editorial Boliviana, Velarde, Bilbao y Cia.

Ortega A. (1987). Insectos nocivos del maíz: una guía para su identificación en el campo. México, D.F.: CIMMYT. 
Perry L. (2006). Early maize agriculture and interzonal interaction in southern Perú, pp. 76-79.

Pickersgill B. (1969). The Archaelogical Record of Chilli Peppers (Capsicum spp) and the Sequence of Plant Domestication in Peru. American Antiquity 34(1), pp. 54-61.

Raimondi A. (1940). El Perú. Tomo I, pp. 326. Lima: Escuela Tipográfica Salesiana.

Reynel C. (2007). Árboles útiles del ande peruano. Lima: UNALM.

\section{ANEXOS}

\section{COLEÓPTERA}

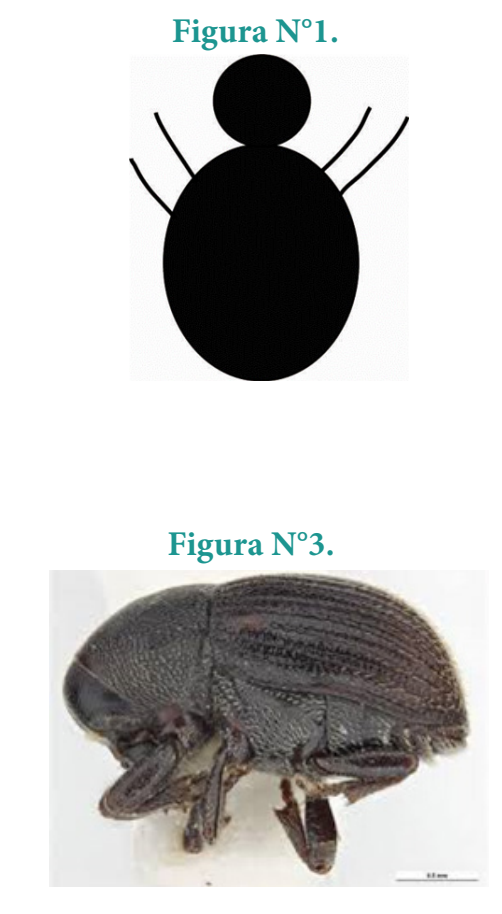

Figura $\mathrm{N}^{\circ} 3$.

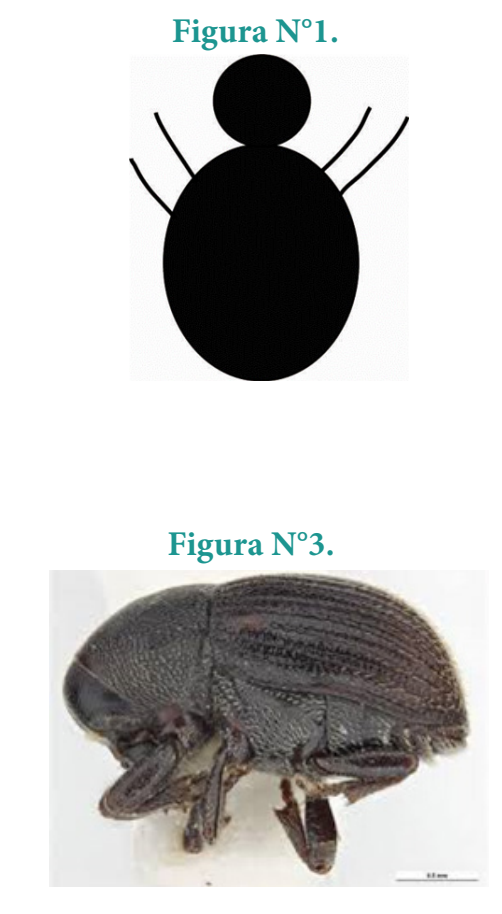

Ruddle K. (1973). The human use of insects: examples from the Yukpa. Biotropica. 5 (2), pp. 94-101.

Vargas W. (1995). Insectos en la Iconografia Inka. Revista Peruana de Entomología 37, pp. 23-29.

Weir G \& Bonavia D. (1985). Coprolitos y dieta del Precerámico Tardío de la Costa Peruana. Bulletin de I'Institut Francais d'Études Andines 14(2), pp. 85-140.

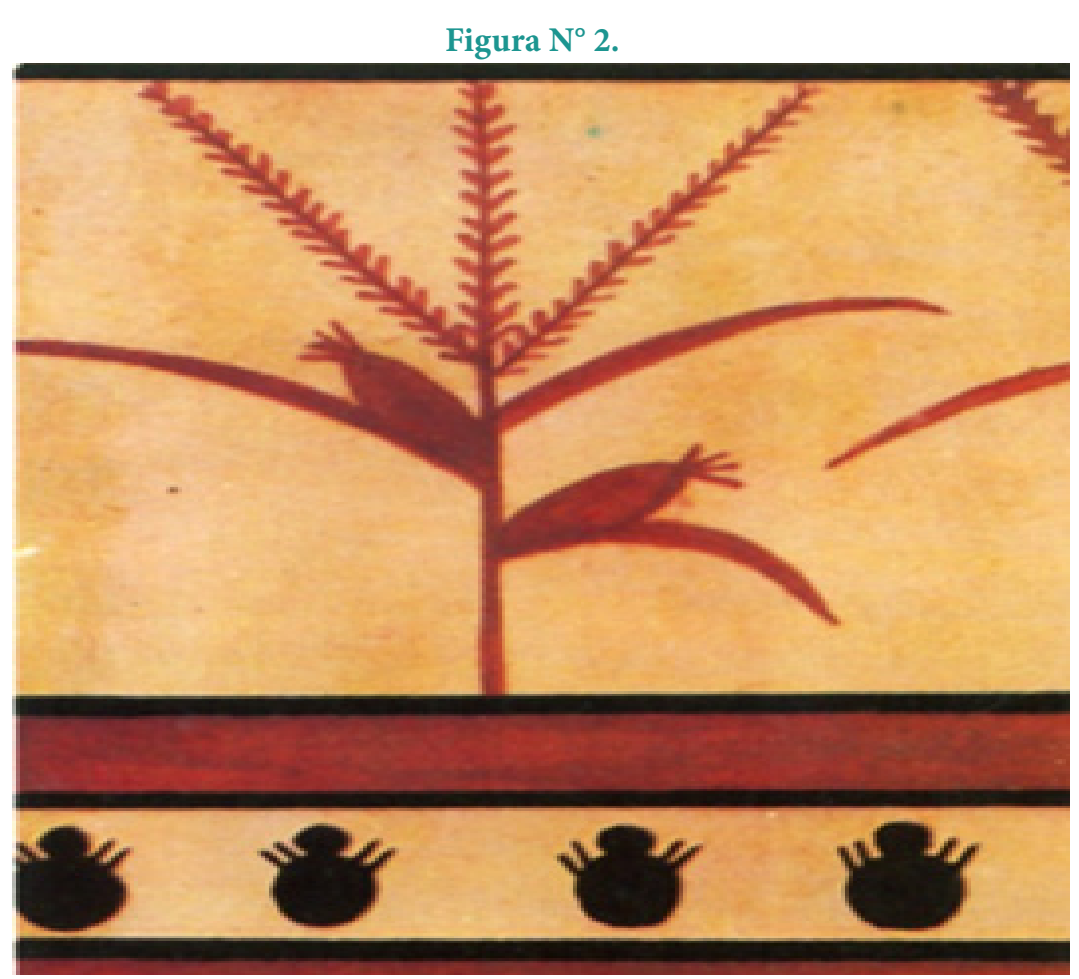

1. Estilización del "Gorgojo del maíz", 2. Iconografía del cultivo de Zea mays L. maíz. En la parte inferior se observa el sustrato y los insectos asociados a éste cultivo, 3. "Gorgojo del maíz" genero Pagiocerus (Curculionidae)

Se asume que podría tratarse del insecto perteneciente al género Pagiocerus de la familia Curculionidae (Figuras 1 - 3), la cual incluye numerosas especies, la mayoría de naturaleza fitófaga, como los gorgojos que son polífagos. En la figura 1 se observa la abstracción de éste insecto en dos partes anatómicas: la cabeza y el resto del cuerpo, no observándose la unión entre estos. Inferimos que el artista no plasmó ésta característica por el reducido tamaño del insecto, pero nos deja entrever el número de individuos y su asociación al cultivo de maíz, el cual está arraigado en la cultura agrícola de la época. Este insecto es conocido comúnmente como el gorgojo del maíz. En general es considerado como una plaga de este cultivo. Es pequeño y generalmente abultado y presenta un caparazón duro, característico del orden Coleóptera. 


\section{COLEÓPTERA}

Figura $\mathrm{N}^{\circ} 4$.

Figura $\mathrm{N}^{\circ} 5$.
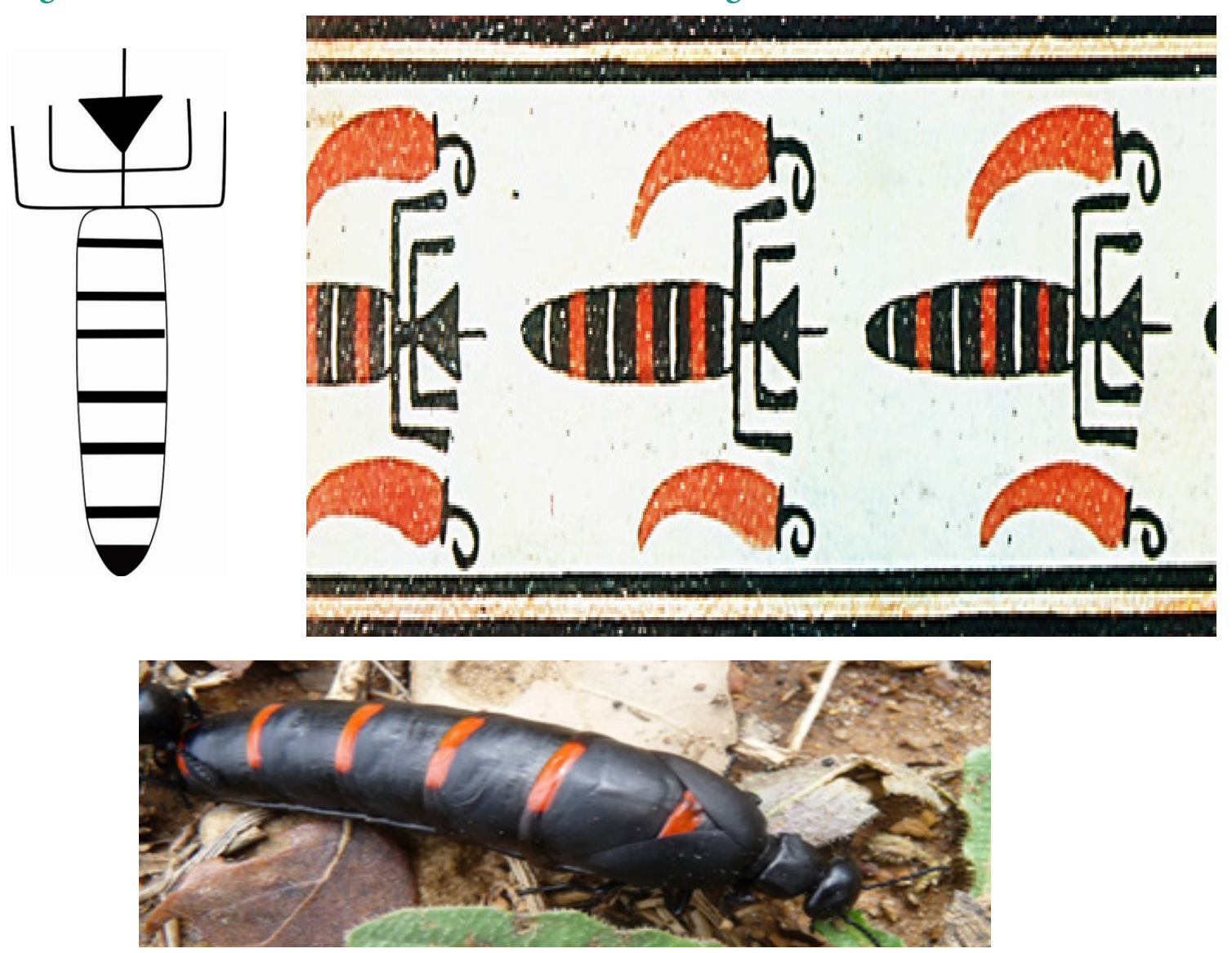

Figura $\mathrm{N}^{\circ} 6$.

4. Estilización del insecto llamado tictiquro, 5. Representación iconográfica, posiblemente Pseudomeloe asociado a frutos de ají Capsicum spp. (Solanaceae), 6. Espécimen del género Pseudomeloe, ticticuro Familia: Meloidae

Los representantes de esta familia son por lo general polífagos, de pequeño a mediano tamaño. La iconografía de este insecto caracteriza a una especie que presenta un abdomen muy pronunciado a diferencia de la cabeza y el tórax juntos. Destaca también unas bandas de color anaranjado en el dorso. Este carácter, en general, tipifica al género Pseudomeloe.

Este grupo, además, son conocidos tradicionalmente como ticticuro y segregan una toxina, la cual estaría relacionada con el tratamiento de la verruga o ticti. La asociación con los ajíes Capsicum spp (Figura 4 - 6) podría estar más vinculado al carácter urticante que produce este fruto, muy parecido al efecto causado por la toxina de este insecto, que a la producción propiamente dicha del mencionado cultivo. Sin embargo, el carácter polífago del ticticuro es determinante para la presencia de cualquier plaga. 


\section{DERMÁPTERA}
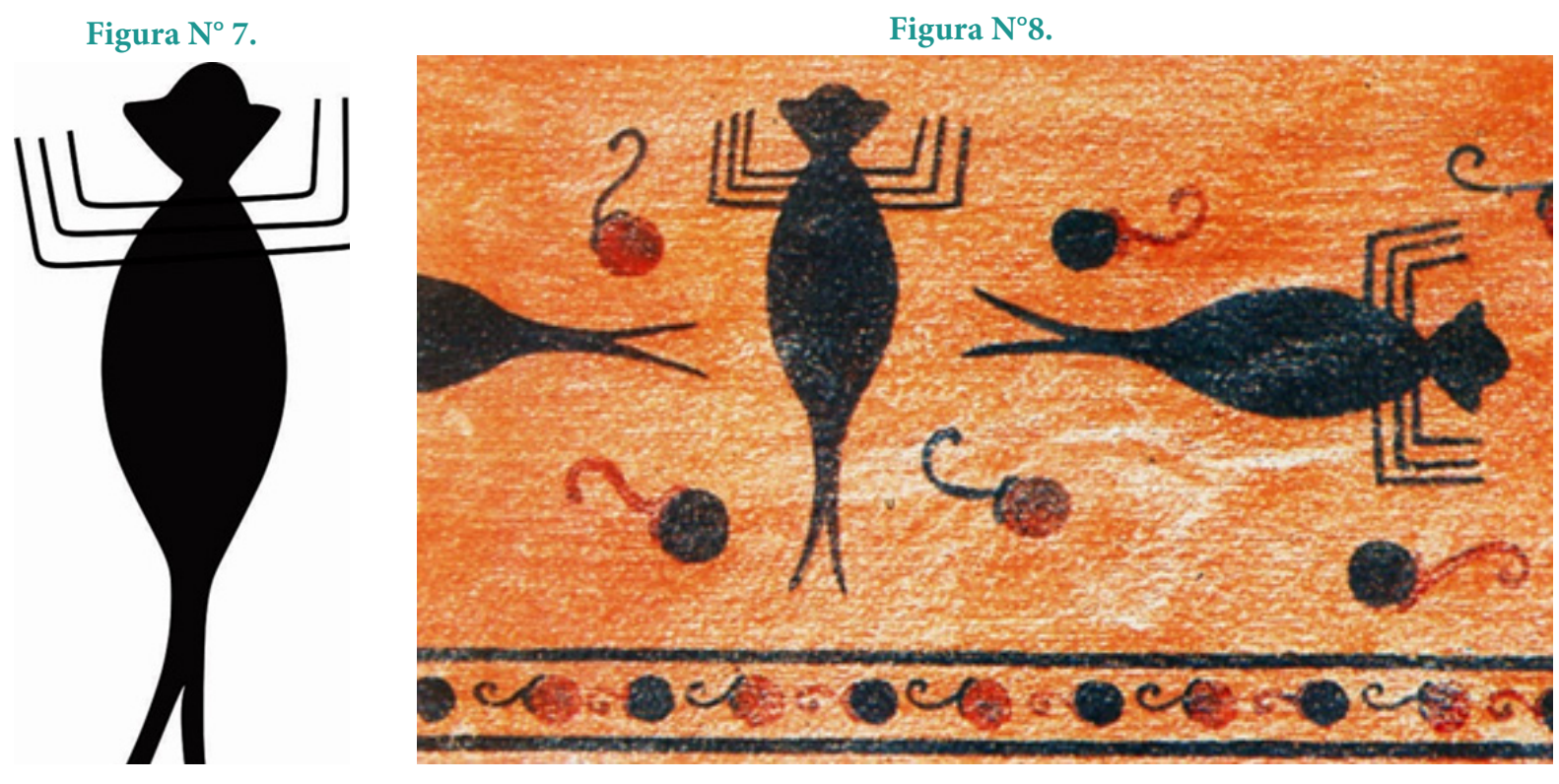

Figura $\mathrm{N}^{\circ} 9$.
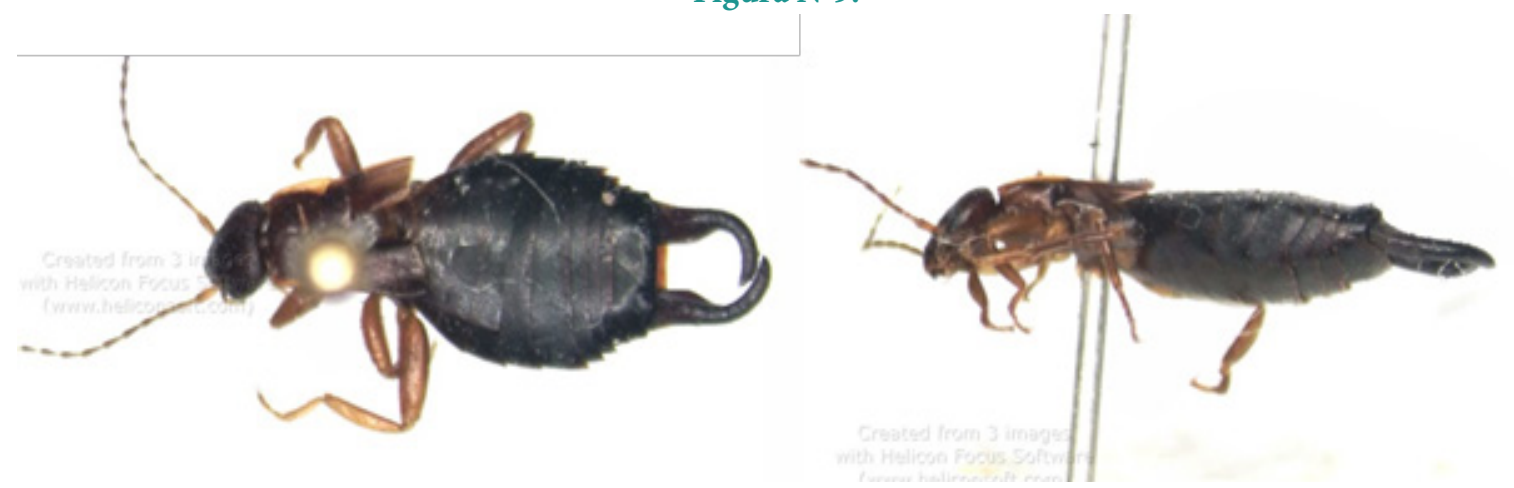

7. Representación estilizada insecto Dermáptero , 8. Iconografía de insectos probablemente del orden Dermáptera. Frutos en baya posiblemente alguna variedad de "rocoto" Capsicum spp (Solanaceae), 9. Insecto tijereta, familia Formiculidae y/o Labiduridae (a.- Vista dorsal, b.- vista lateral)

Este grupo de insectos se reconocen por la presencia de (cercos) en forma de tijerillas en la parte caudal. De ahí la denominación de tijeretas. Esta modificación es utilizada para defensa y caza de presas.

Frecuentan lugares húmedos, hecho que podría estar vinculado con el cultivo del rocoto, medio al cual favorece su desarrollo. Este grupo de insectos actuarían como predadores naturales de otros insectos. También es conocido como escorpión de riberas, ya que frecuentan las riberas de los ríos, pudiendo hasta flotar en ellos. Son de hábito nocturno. Se agrupan abundantemente en torno a animales muertos. (Figuras 7 - 9) 


\section{DÍP TERA}

Figura $\mathrm{N}^{\circ} 10$.

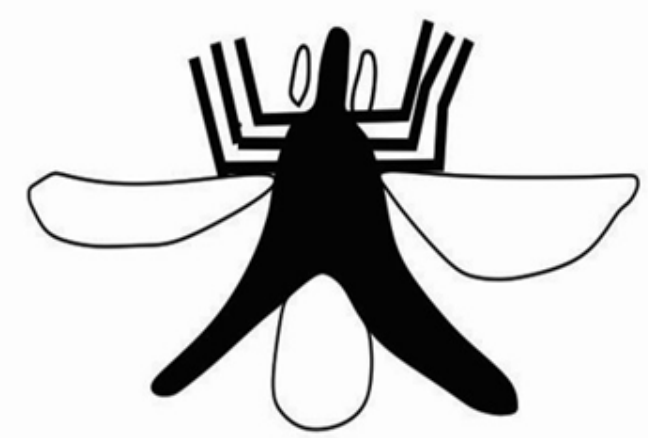

Figura $\mathrm{N}^{\circ} 11$.

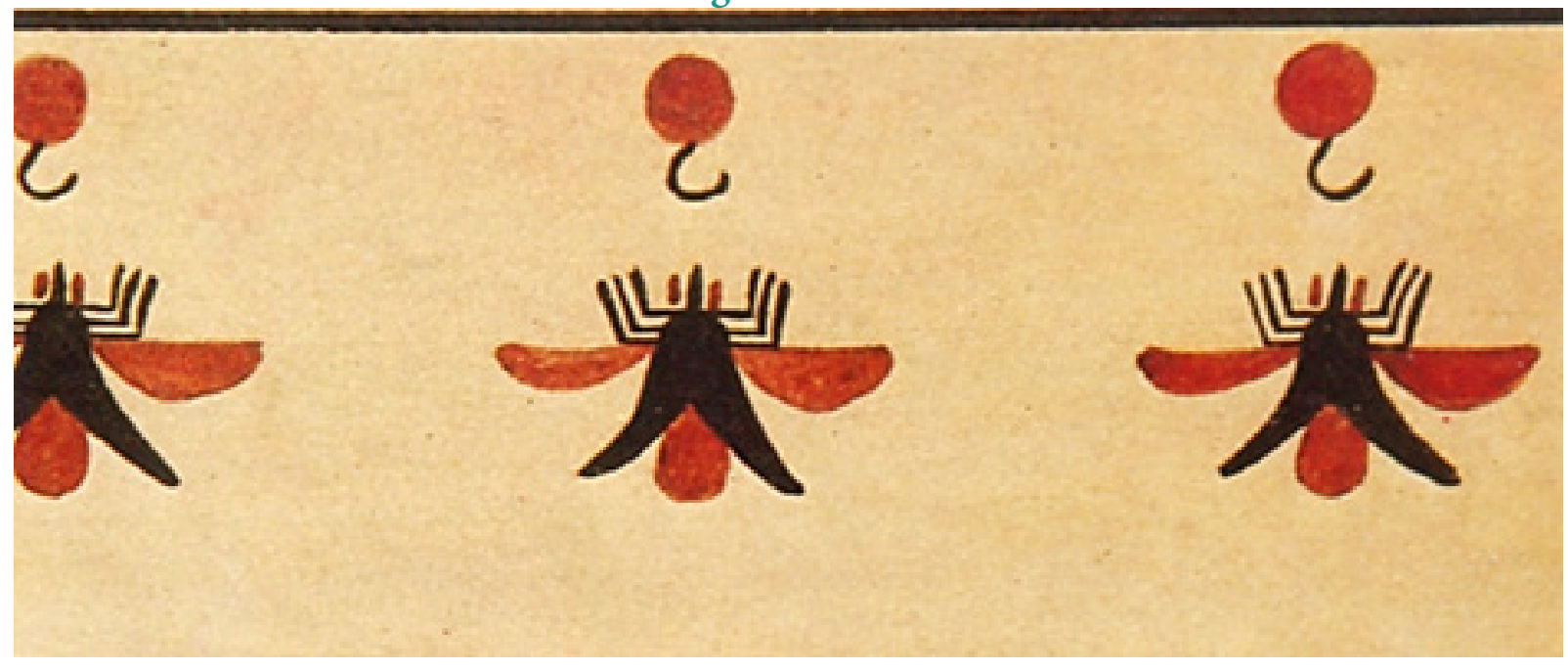

10. Estilización, posiblemente mosca de la fruta, 11. Iconografía de insectos dípteros, familia tephritidae, asociado a frutos probablemente rocoto Capsicum spp (Solanaceae)

La iconografía muestra a un posible Díptero. Este orden incluye a moscas, mosquitos y zancudos. La anatomía de este insecto posee 3 pares de patas y el despliegue de un par de alas observadas generalmente en moscas pequeñas como el de la fruta. Estos especímenes probablemente pertenezcan a la familia Tephritidae. Sin embargo, la postura "en vuelo" podría suponer que se trata de pequeños abejorros (Hymenóptera), buscadores de néctar.

En general, este grupo de insectos están asociados con la dispersión y la polinización de plantas. Los frutos rojos con pedúnculos negros curvos representarían a bayas de Prunus spp. (Rosaceae) o más probablemente podrían asociarse con frutos de Capsicum spp. (Solanaceae), aunque estos, no presentan el cáliz persistente que caracteriza a éste género (Figuras 10,11). 


\section{DÍP TERA}

Figura $\mathrm{N}^{\circ} 12 \mathrm{a}$.

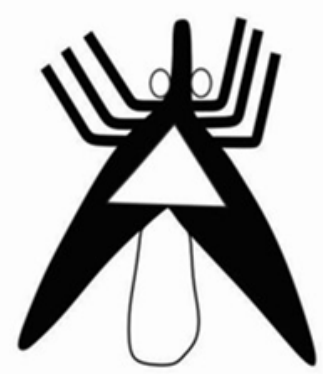

Figura $\mathrm{N}^{\circ} 12 \mathrm{~b}$.

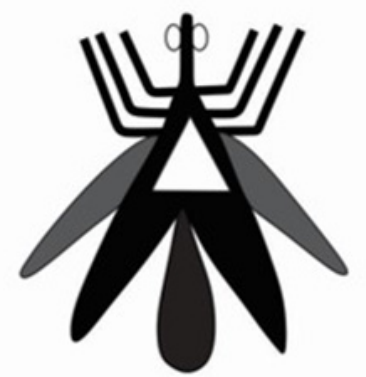

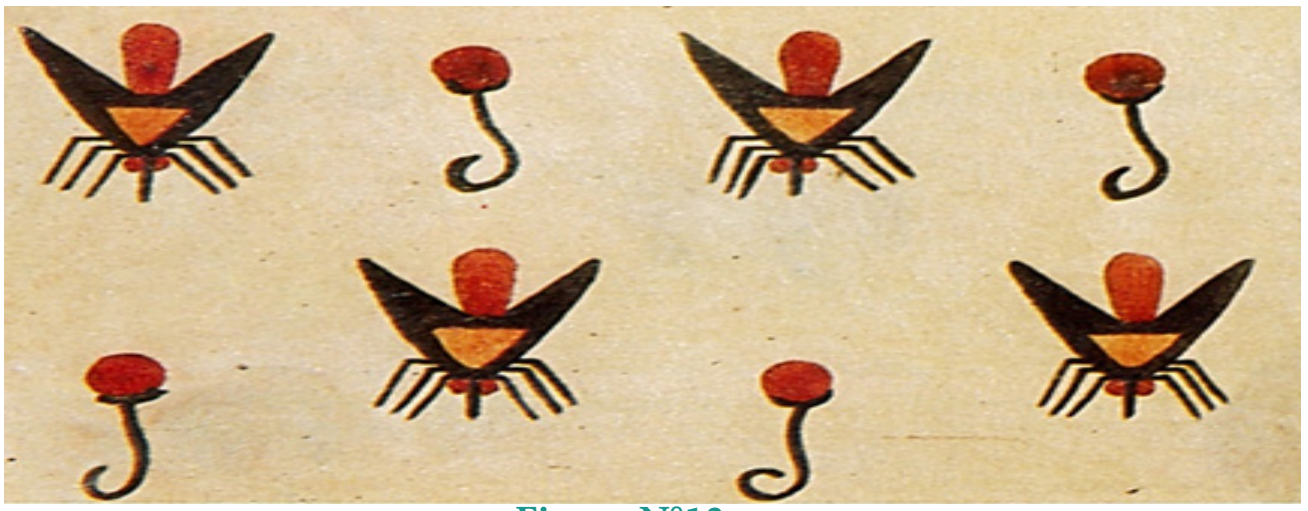

Figura $N^{\circ} 13 a$.

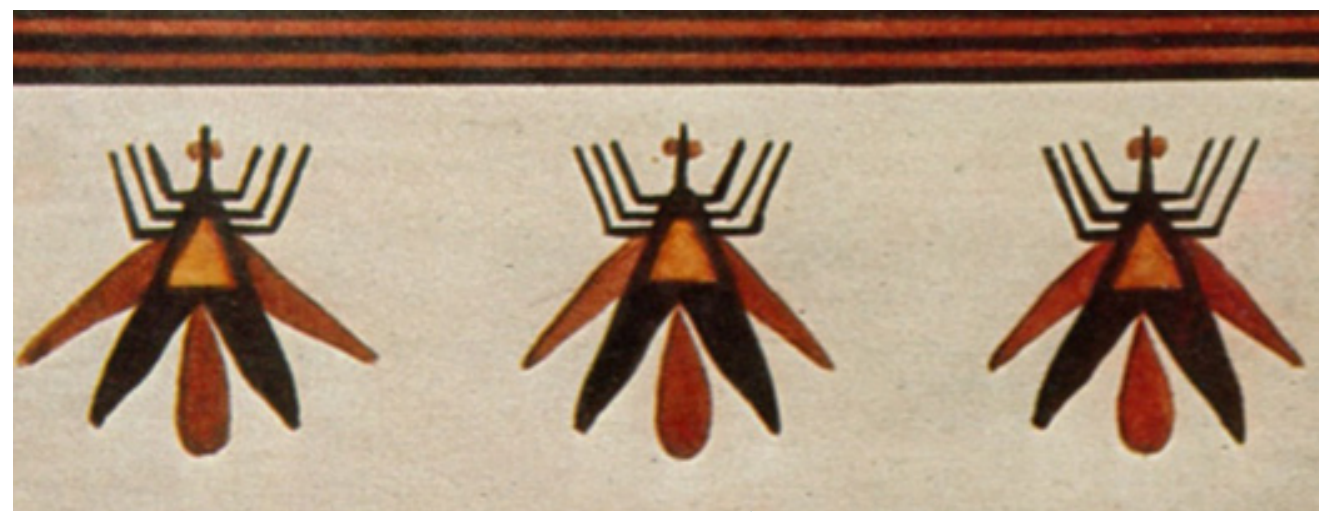

Figura $\mathrm{N}^{\circ} 13 \mathrm{~b}$.

12a. Estilización de un mosquito, 12b. Estilización de un mosquito, 13a. Iconografía de mosquitos asociado a frutos de rocoto posiblemente representantes de la familia Tephritidae, 13b Iconografía de mosquitos posiblemente representantes de la familia Tephritidae.

Las láminas hacen referencia a mosquitos pequeños, el detalle -forma triangular- en el dorso superior, caracteriza a este grupo de dípteros. La representación de la asociación con frutos de cáliz persistente, pedicelos oscuros y curvos, infieren que se trataría de Capsicum spp. (Figura 13a). La asociación con este producto, estaría relacionado con los contrastes del color del fruto, que el artista percibió en el abdomen y ojos del insecto; el color del abdomen nos deja entrever que se tratarían de mosquitos hematófagos los cuales no están directamente vinculados con la acción polinizadora que ejercen otros insectos del grupo de los dípteros. En la Figura Figura 13b se aprecia el mismo tipo de insectos con alas desplegadas, comunes en los ámbitos de montaña y puna de nuestro medio. Estos son conocidos como ch'itis y pumahuacachis. 


\section{DÍP TERA}

Figura $\mathrm{N}^{\circ} 14 \mathrm{a}$.

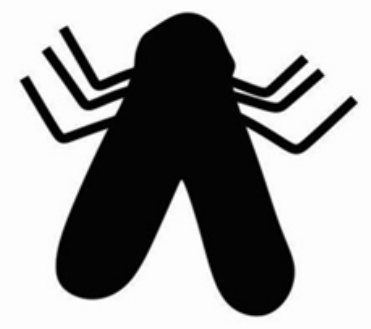

Figura $\mathrm{N}^{\circ} 14 b$.

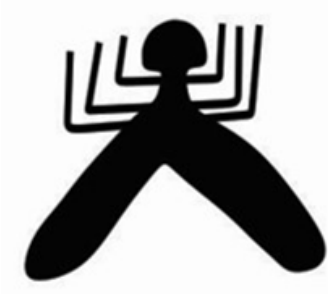

Figura $\mathrm{N}^{\circ} 15 \mathrm{a}$.
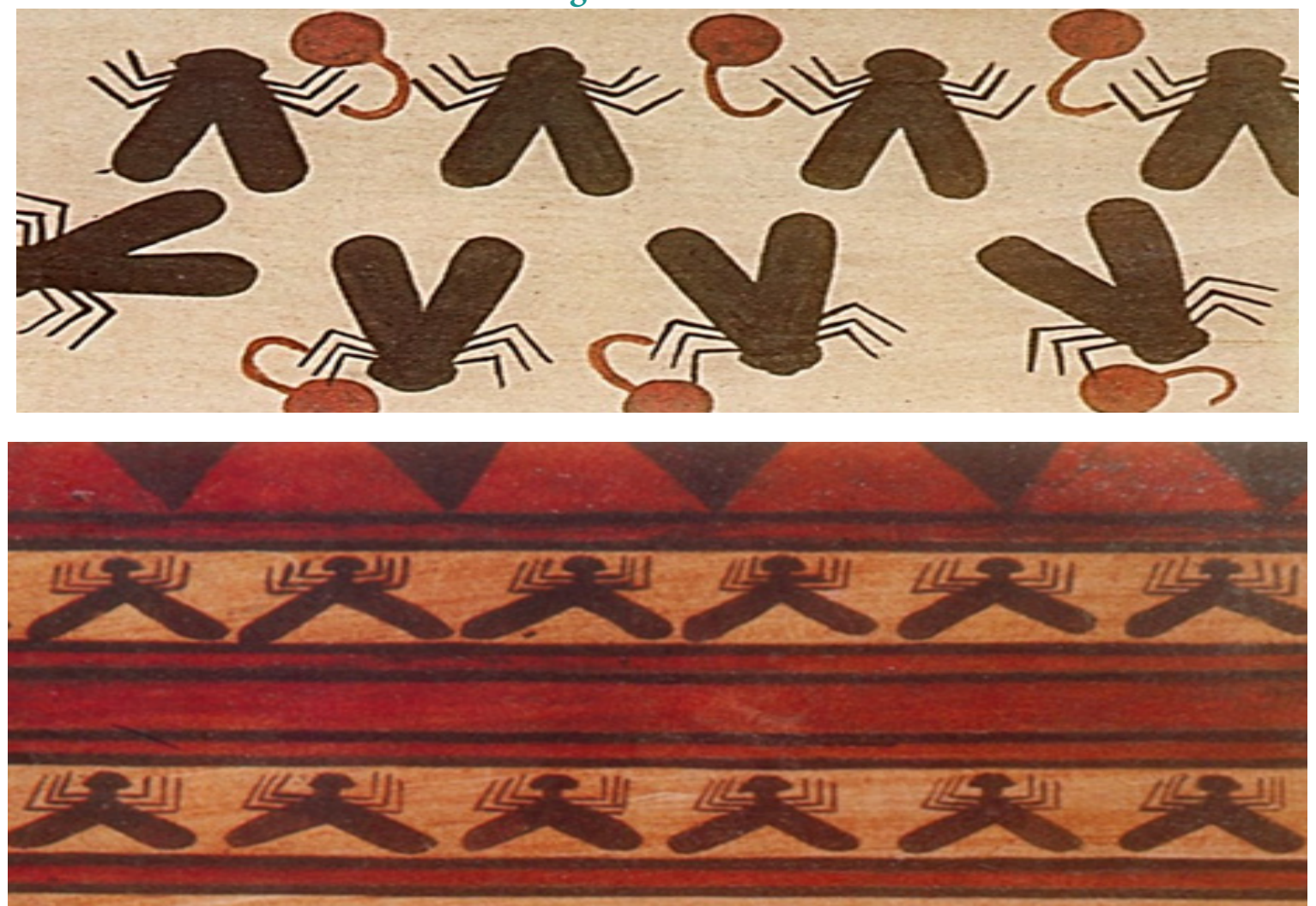

Figura $\mathrm{N}^{\circ} 15 \mathrm{~b}$.

14a. Posible tábano estilizado, 14b. Moscas y tábanos estilizados, 15a. Iconografía de moscas grandes, posiblemente tábanos. Frutos en baya parecidos al rocoto Capsicum spp, 15b. Iconografía de moscas ch’uspi

Probablemente, la representación de moscas grandes, conocidas como tábanos, en el que se incluye a los chuspi, nombre que es atribuido a la mayoría de éstos dípteros oscuros, que casi siempre son atraídos por colores llamativos como el que proveería los frutos rojos de esta baya Figura 15a). Este hecho explicaría su asociación.

En la Figura 15b, están representadas moscas un poco más pequeñas que se habrían constituido como parte del quehacer domestico de la época. 


\section{DÍP TERA}

Figura $\mathrm{N}^{\circ} 16$
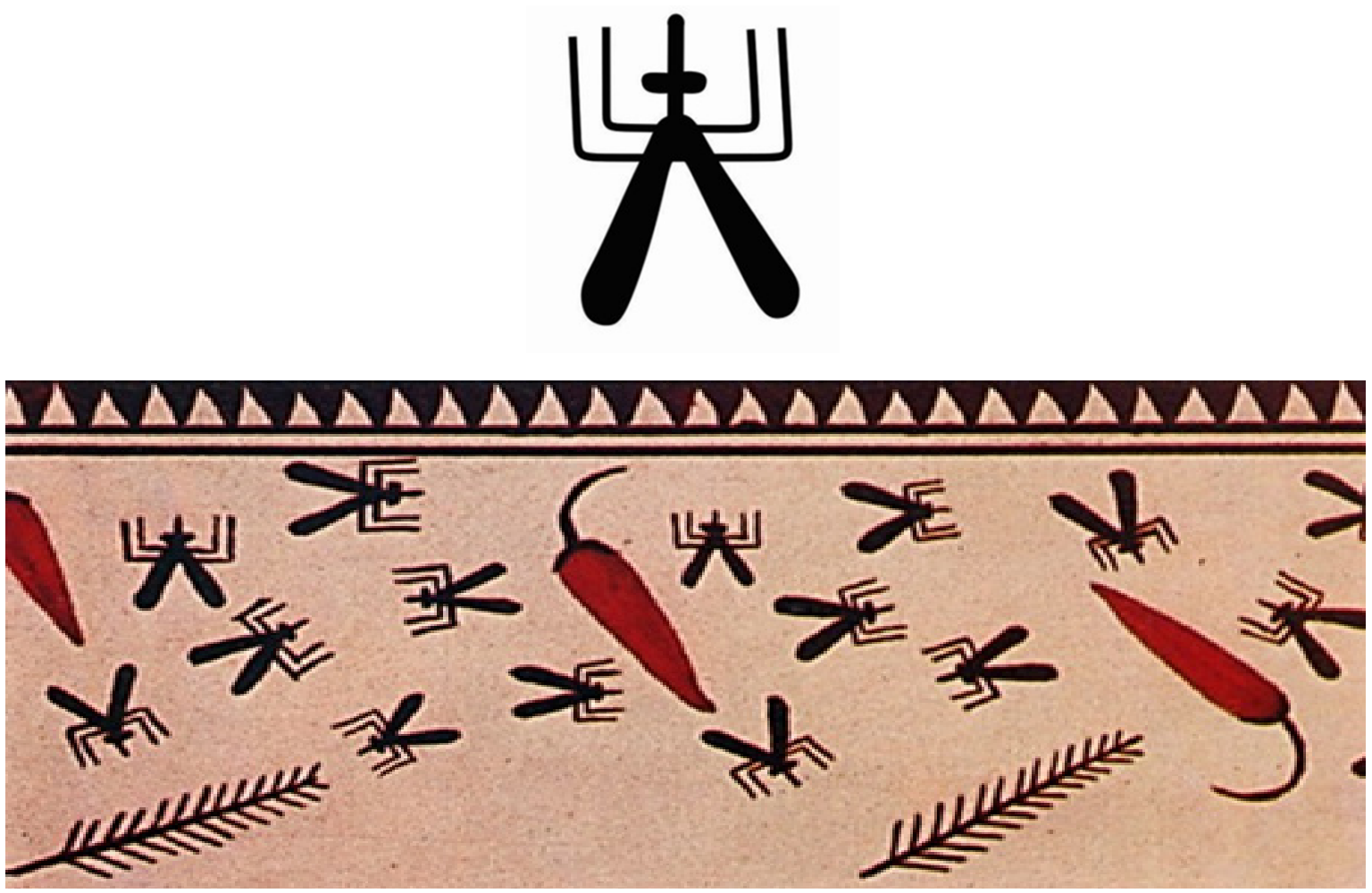

Figura $\mathrm{N}^{\circ} 17$

16. Figura estilizada mosquito zancudo, 17. Representacion de dípteros, probablemente mosquitos asociados a frutos de ají, Capsicum sinense Jacq. (Solanaceae)

La represenentacion muestra a varios insectos mosquito en vuelo errático, alrededor de ajíes. Estos frutos guardan estrecha relacion por su forma delgada y alargada, con la especie Capsicum sinense Jacq. (Solanaceae). Esta especie de ají fue domesticado en la parte baja del Amazonas y posteriormente alcanzó la costa, al mismo tiempo que la aparición de la cerámica (Pickersgill 1969).

Esta investigadora, también refiere que esta especie fue cultivada por pobladores de Yarinacocha y Kotosh, en el flanco oriental de los Andes alrededor de 2000 a.C. Los mosquitos asociados a este fruto, probablemente jugaron un rol importante en la polinización de esta especie (Figuras 16, 17). 


\section{DÍP TERA}

Figura $\mathrm{N}^{\circ} 18 \mathrm{a}$.

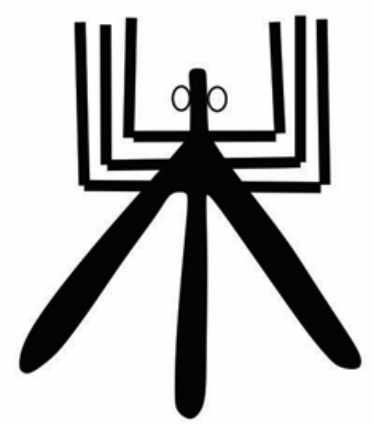

Figura $\mathrm{N}^{\circ} 18 \mathrm{~b}$.

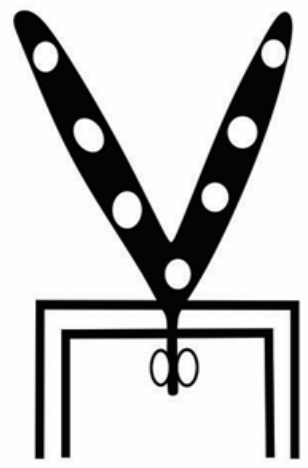

Figura $\mathrm{N}^{\circ} 19 \mathrm{a}$.
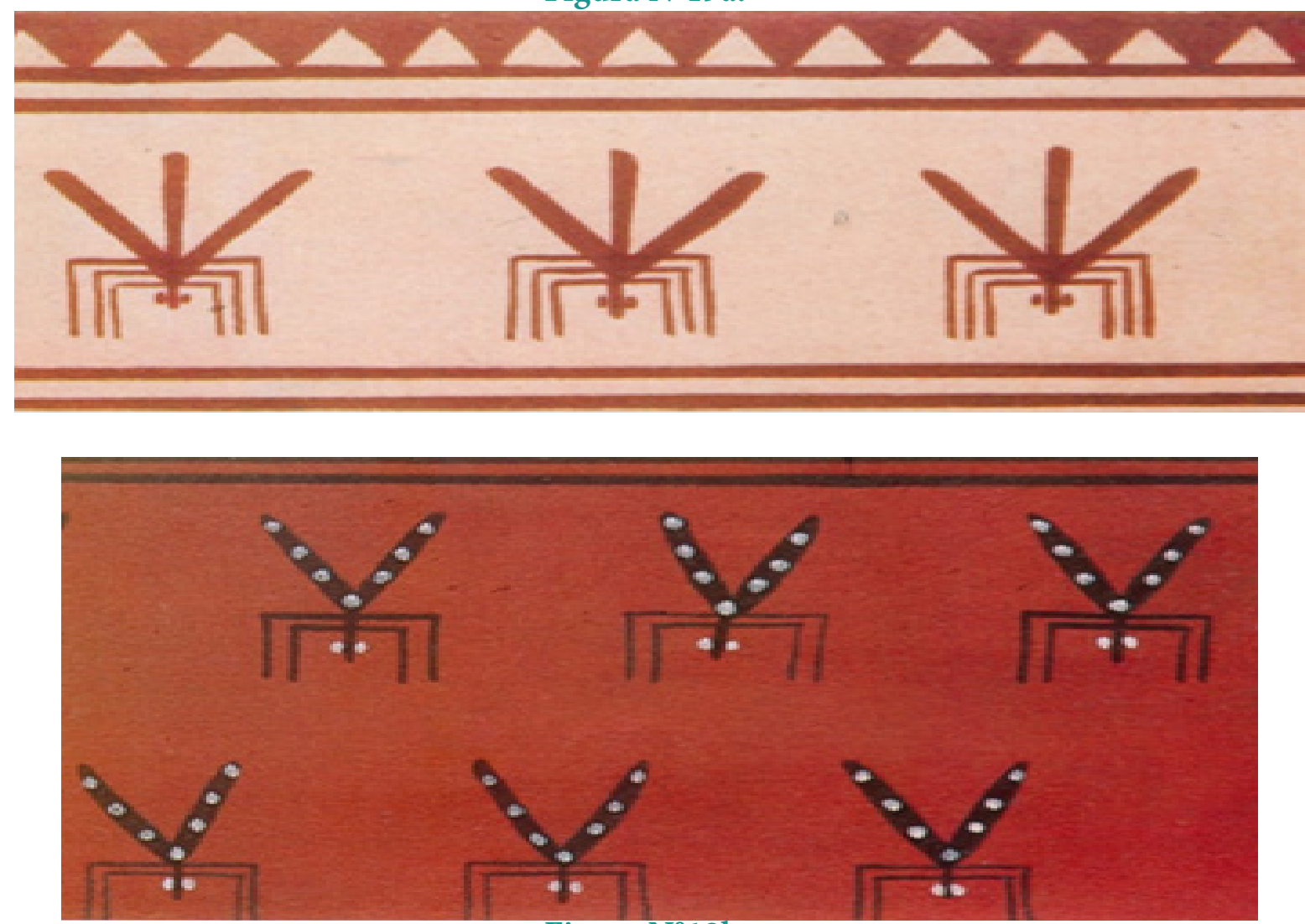

Figura $\mathrm{N}^{\circ} 19 \mathrm{~b}$.

18a. Estilización de mosquito - zancudo con las alas abiertas, 18b. Estilización de un mosquito - zancudo, probablemente Tipulidae, 19a. Representación de mosquitos - zancudo, 19b. Representación de mosquitos - zancudo (Tipulidae)

Estas representaciones de dípteros, muestran a mosquitos tipo zancudo, caracterizados por presentar cuerpo delgado y patas alargadas, así como el aparato bucal "chupador" pronunciado. Los miembros de la familia Tipulidae, además, presentan manchas en las alas; por ahí la asociación con estos (Figura 18 - 19).

La mayoría de estos insectos son hematófagos, se alimentan de la sangre de varios mamíferos, incluidos el hombre. Este último hecho les convierte en los principales causantes y transmisores de males como la malaria y la leishmaniosis, frecuente en nuestro medio. 


\section{DÍP TERA}

Figura $\mathrm{N}^{\circ} 20$.
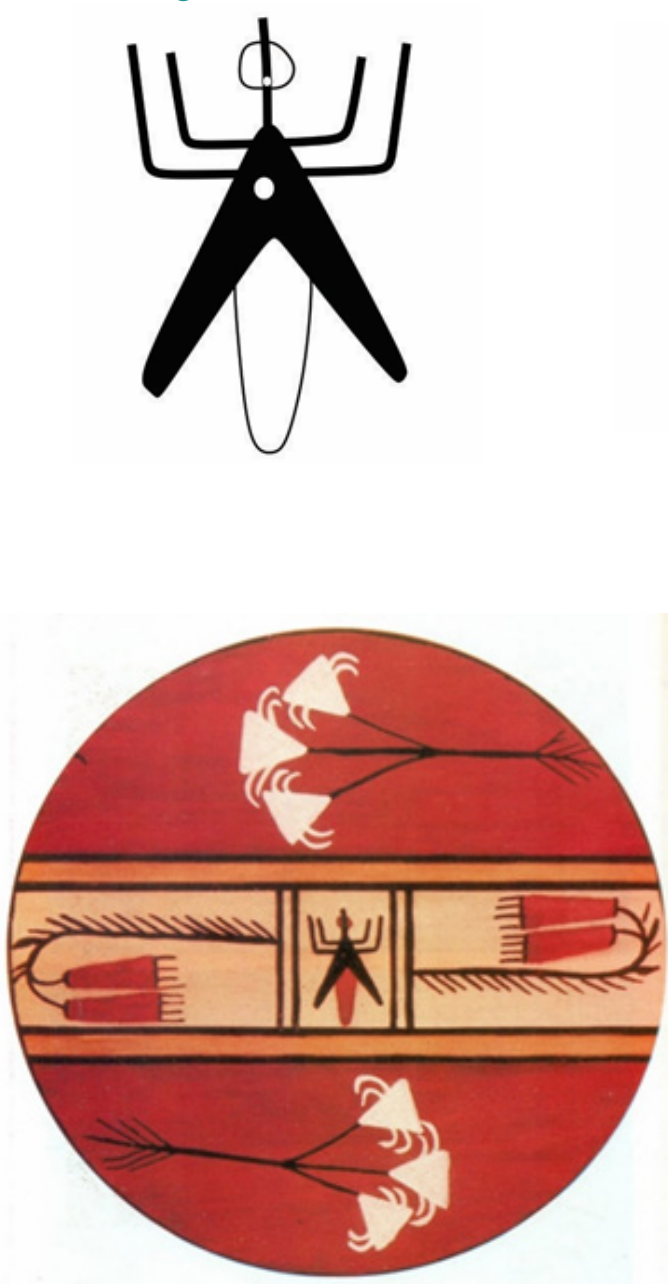

Figura $\mathrm{N}^{\circ} 21 \mathrm{a}$.
Figura $\mathrm{N}^{\circ} 20 \mathrm{~b}$.

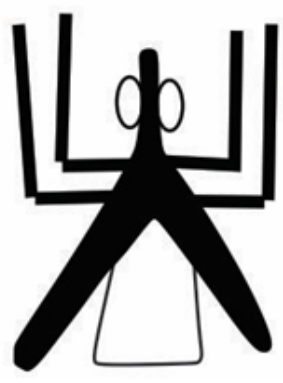

Figura $\mathrm{N}^{\circ} 20 \mathrm{c}$.

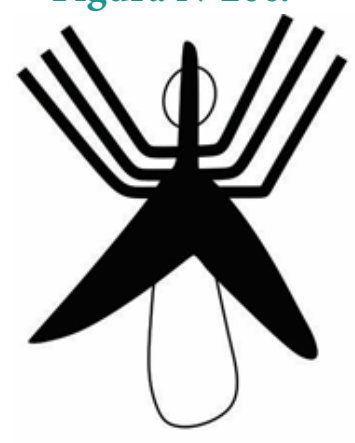

Figura $\mathrm{N}^{\circ} 21 \mathrm{~b}$.

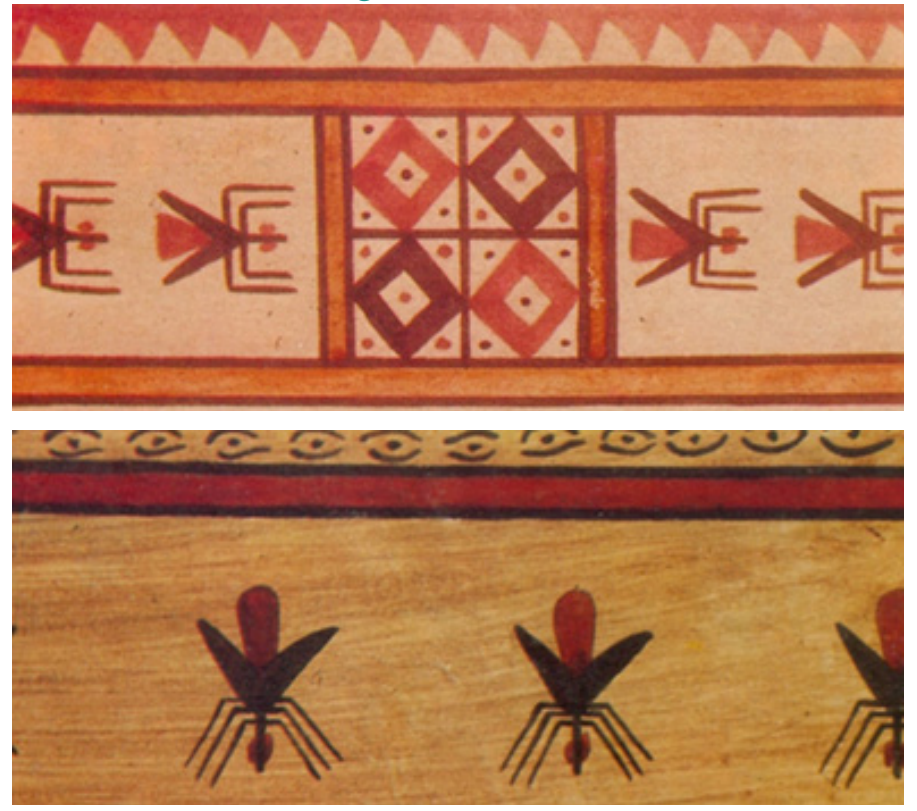

Figura $\mathrm{N}^{\circ} 21 \mathrm{c}$.

20(a-b-c) Estilización de 3 tipos diferentes de mosquitos, 21a. Iconografía de mosquito, probablemente un agente polinizador. Flores blancas de Ismene spp (Amarillidaceae). Flores tubulares de Bomarea spp (Alstroemeriaceae), 21b. Iconografía de mosquito, 21c. 3ra variedad de mosquitos, con el abdomen rojo, probablemente hematófago 


\section{HYMENÓPTERA}

Figura $\mathrm{N}^{\circ} 22 \mathrm{a}$.

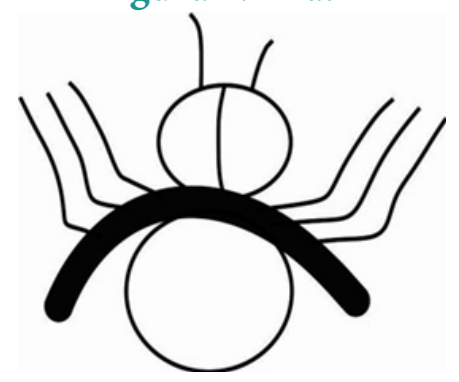

Figura $\mathrm{N}^{\circ} 22 \mathrm{~b}$.

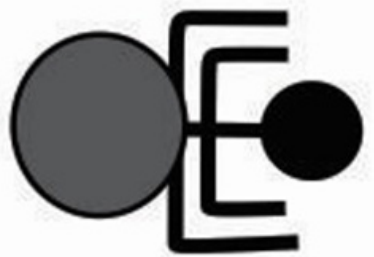

Figura $N^{\circ} 23 a$.
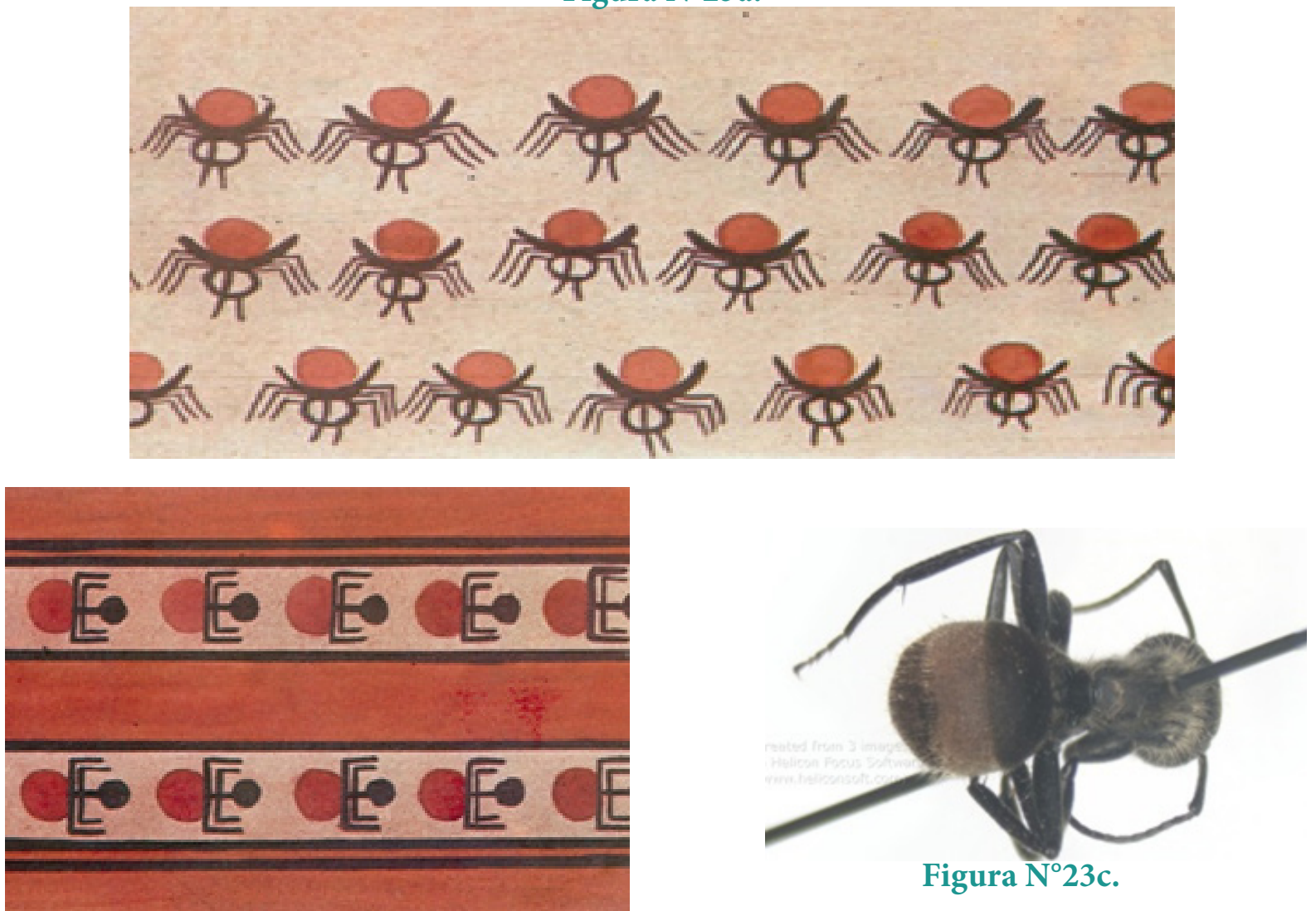

Figura $\mathbf{N}^{\circ} 23 \mathrm{c}$.

Figura $N^{\circ} 23 b$.

22a. Estilización de una hormiga, 22b. Estilización - hormiga desplazándose, 23a. Grupo de hormigas probablemente pertenecientes a la familia Formicidae, 23b. Hormigas desplazándose en fila ordena, 23c. familia Formicidae

El orden Hymenóptera, además de las abejas, incluye a un vasto grupo de insectos conocidos como hormigas o sisi en el idioma quechua. Estos a su vez representan variantes como las hormigas cortadoras de hojas, tradicionalmente llamadas kukis, las hormigas guerreras chaco, el solitario sapanqari o hisula y las tangaranas. Estas últimas de hábito mirmecófilo, viven en interacción co-evolutiva con el árbol Triplaris peruviana Fisch. \& Meyer ex C.A. Meyer (Polygonaceae) conocido como palo santo. Igualmente, destaca la asociación mutualista entre hormigas del género Azteca y el toroc o cetico Cecropia spp. (Urticaceae), representada por 03 especies en el ámbito del SHMP, así como con la orquídea Schomburgkia spp.

En general, este grupo de insectos protegen al vegetal del ataque de herbívoros, teniendo como beneficio un lugar donde habitar. En la iconografía inka (Figuras 22,23) se aprecia a un grupo de hormigas 
con el cuerpo dividido en tres partes claramente diferenciables (cabeza, el tórax y el abdomen). En la cabeza se aprecia las antenas, en el tórax se pueden diferenciar los tres pares de patas y el abdomen con su forma ovoide diferenciada. Esta característica última podría tipificar al género Camponotus spp., familia Formicidae (Figura 23c), la cual representa a varias especies ampliamente distribuidas en la región andina, además de estar vinculadas con la agricultura.

\section{HYMENÓPTERA}
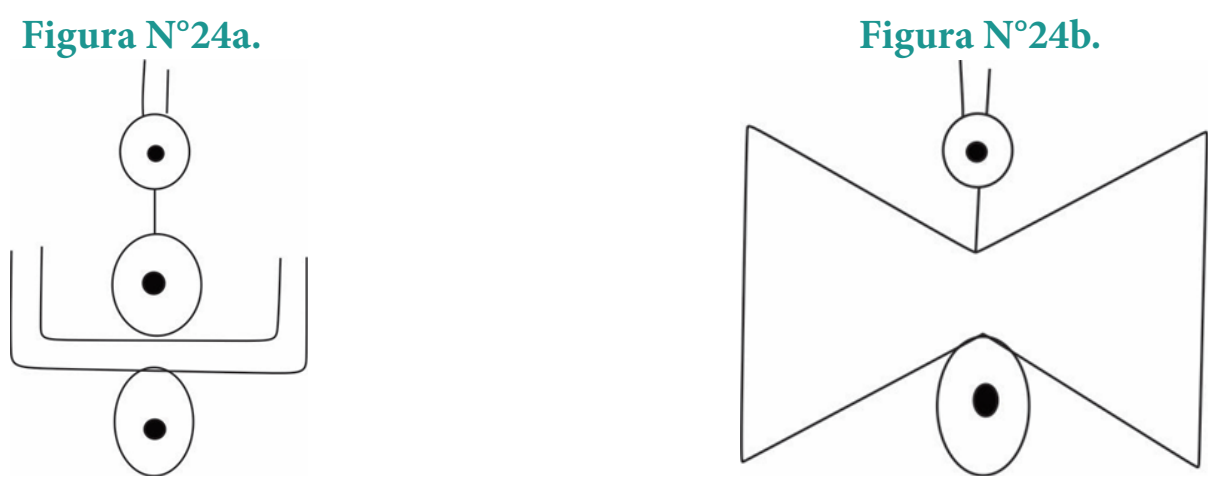

Figura $\mathbf{N}^{\circ} 25$.

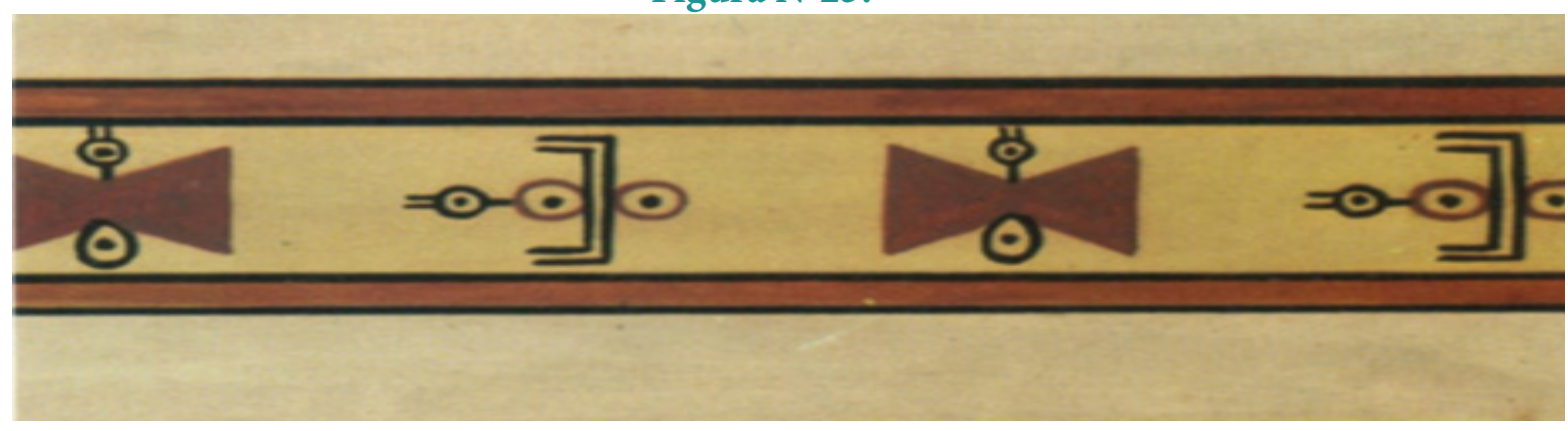

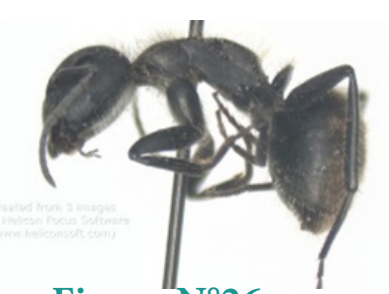

Figura $\mathrm{N}^{\circ} 26$.

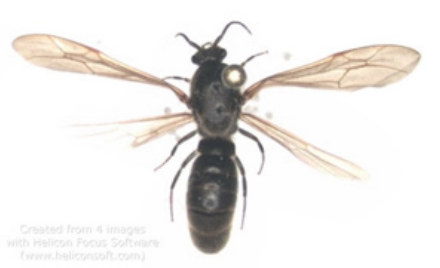

Figura $\mathbf{N}^{\circ} 27$.

24a. Hormiga estilizada, 24b. Hormiga estilizada con alas, 25. Iconografía de hormigas alternando con estadios de ejemplares voladores, 26. Forma no alada, 27. Forma alada (Formicidae)

La representación iconográfica muestra la presencia de dos estadios biológicos de hormigas. Este hecho singular está documentado en casi todos los grupos de hormigas, vinculado con el apareamiento y migración. Esto se produce en intervalos de cambios de estación climática y principalmente después de las lluvias. Es probable que el artista asociara la ocurrencia de veranillos con la presencia de hormigas aladas -a manera de predicción climática.

Las características fenotípicas de estos individuos podrían asociarse con representantes de la familia Formicidae, en general. Estos insectos alados tienen un corto periodo de vida y se presentan en machos y hembras (Figura 27). 


\section{MEGALÓPTERA}

Figura $\mathrm{N}^{\circ} 28$.

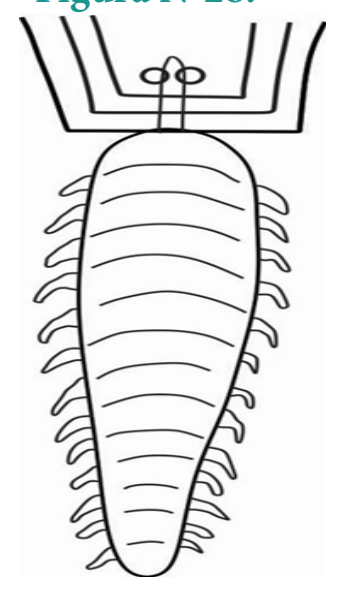

Figura $\mathrm{N}^{\circ} 29$.
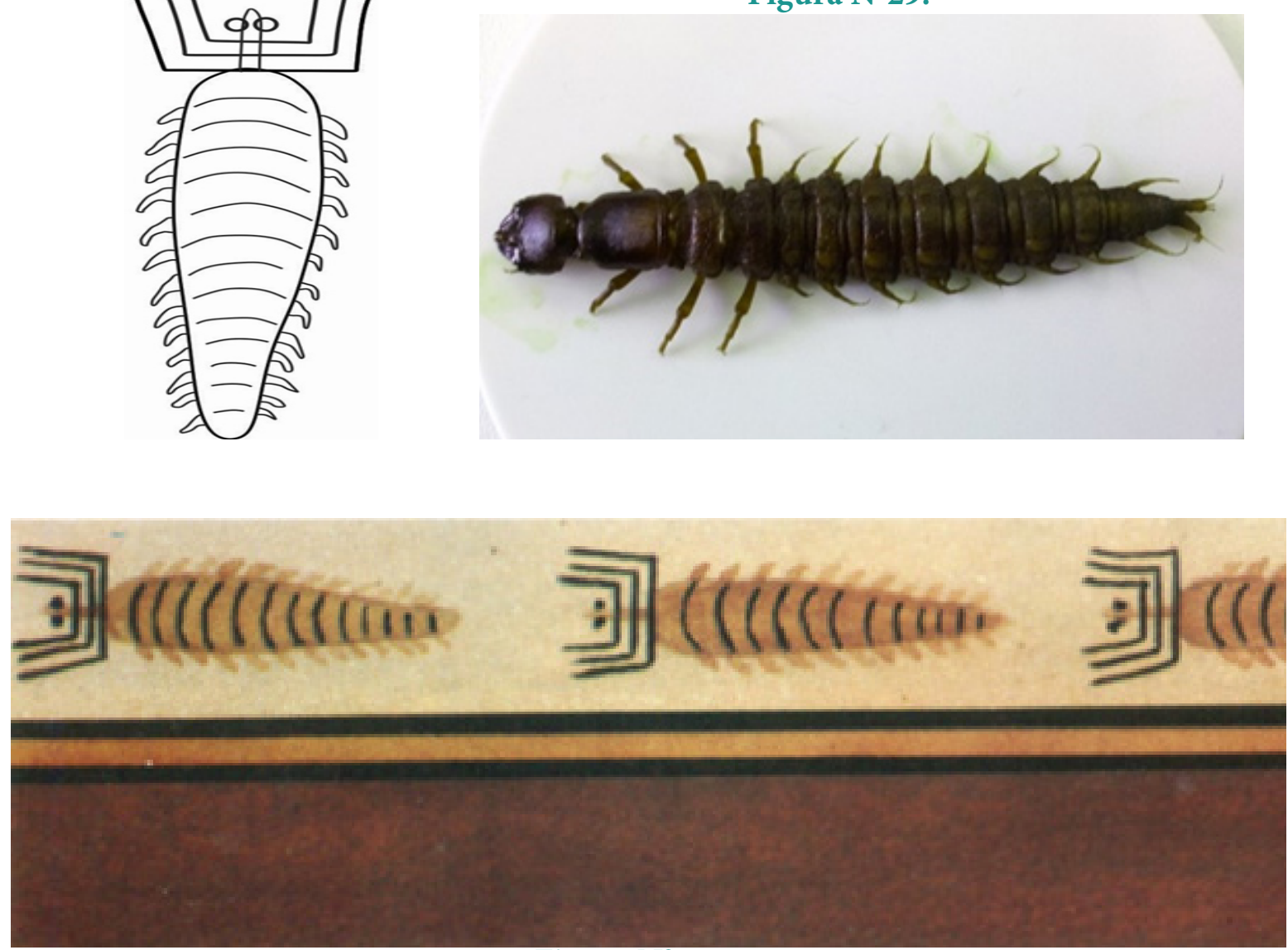

Figura $\mathbf{N}^{\circ} 30$.

28. Estilización del insecto Corydalus, 29. Iconografía probablemente Corydalus spp. (Corydalidae), 30. Individuo del género Corydalus, familia Corydalidae

La iconografía probablemente representa al insecto Megalóptero del género Corydalus. Esta aproximación taxonómica se afianza por el hecho que solo existe este género en nuestro medio. Son de tamaño mediano a grande, hasta $7 \mathrm{~cm}$.

La forma larval presenta "setas" a modo de espinas en cada segmento abdominal y es comúnmente utilizado como sebo de pesca. También es considerado como indicador de aguas de buena calidad.

El aspecto del adulto es un tanto grotesco, causando temor por las grandes mandíbulas que expone, así mismo emite un olor nauseabundo (Figura 28 -30). 


\section{HEMÍPTERA}
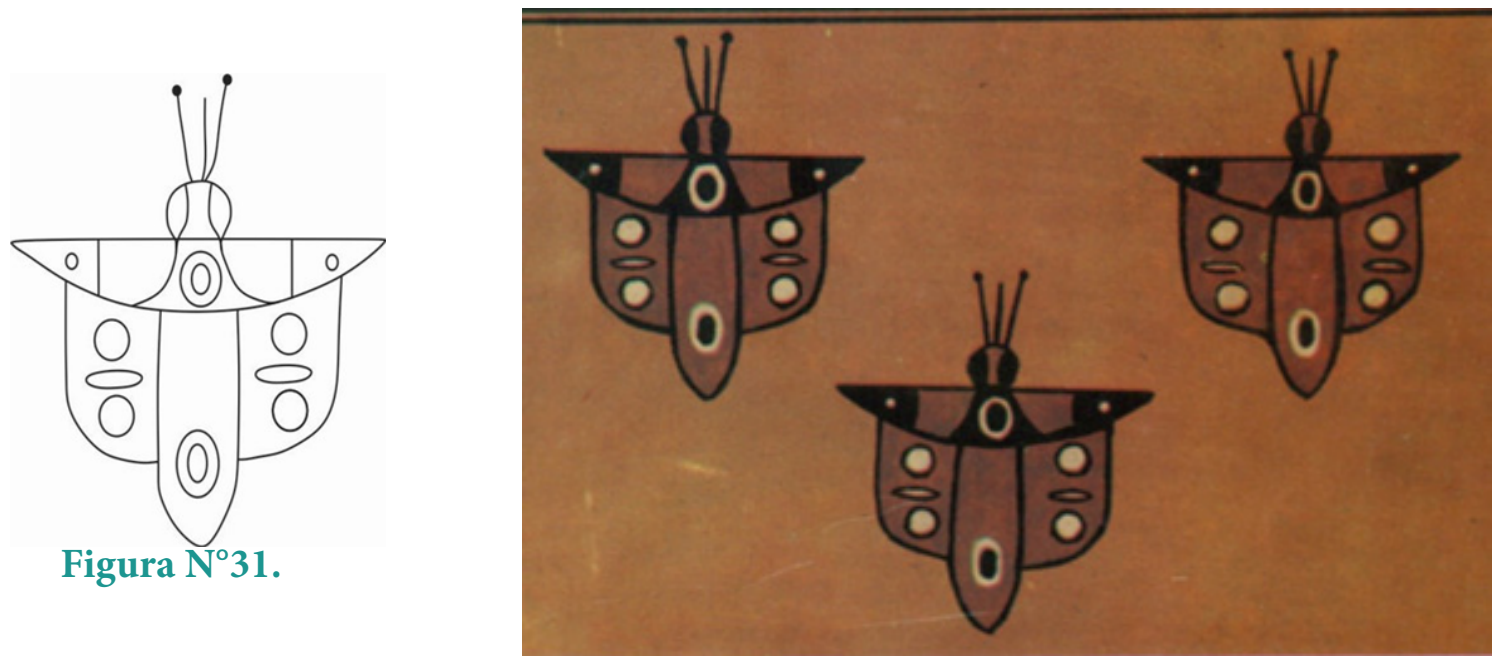

Figura $\mathrm{N}^{\circ} 32$.

31. Estilización de un probable Pentatómido (Chinche), 32. Representación iconográfica de posibles insectos chinche

La iconografía representa insectos de la familia Pentatomidae. Esta agrupa a chiches, en su mayoría fitófagos. Viven en grupos de varios individuos, alimentándose principalmente de hojas tiernas. Ostentan colores muy llamativos y emiten un hedor nauseabundo a la presencia de peligro. En nuestro medio son conocidos comúnmente como paya-paya. En general, algunas especies son causantes de enfermedades en el hombre, como el mal de Chagas, transmitido por la picadura del chinche conocido como vinchuca, endémica de climas cálidos, como el bosque seco de la región Apurímac (Figuras $31,32)$.

\section{LEPIDÓPTERA}
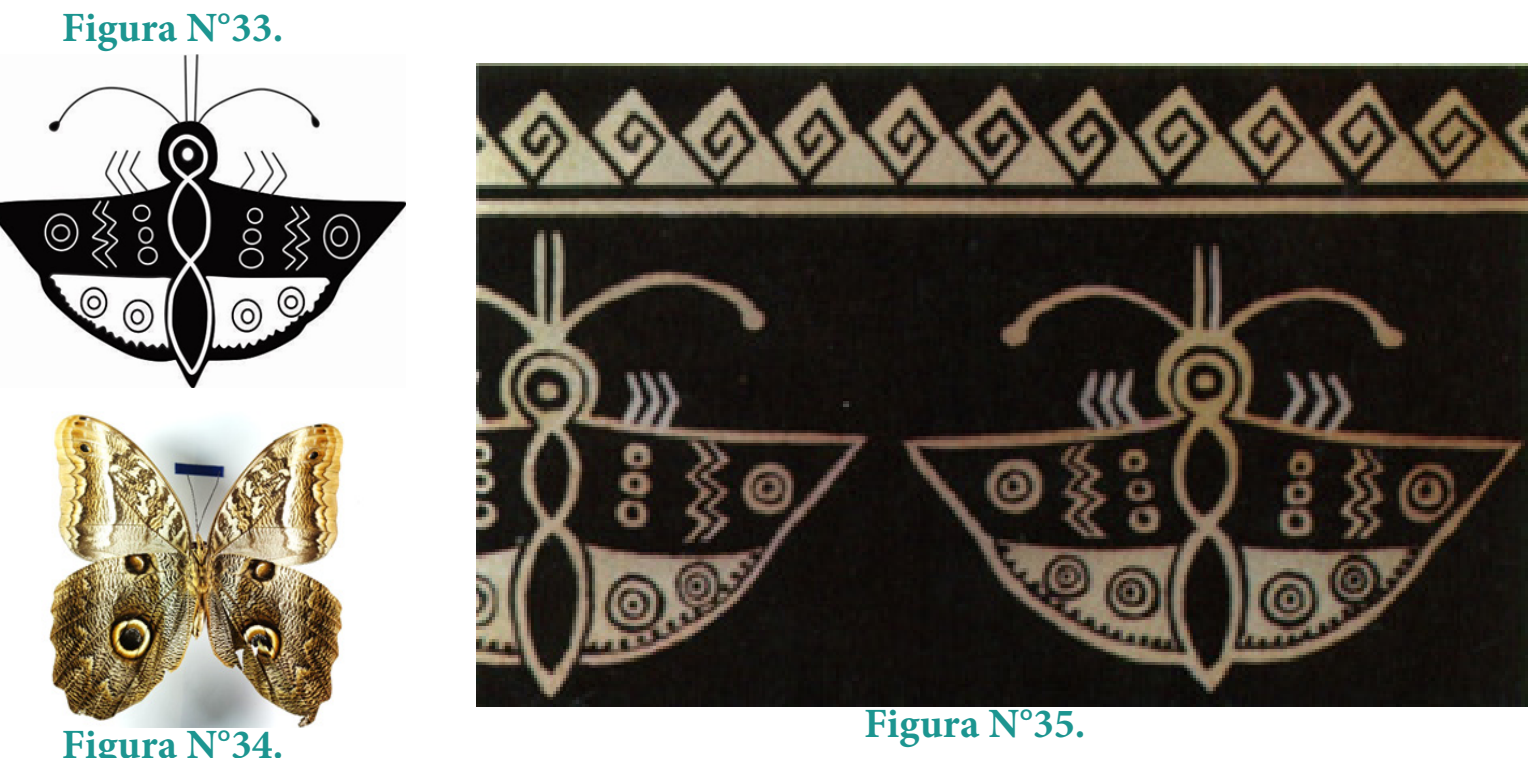

Figura $\mathrm{N}^{\circ} 35$.

33. Estilización iconografía de una mariposa diurna, 34. Iconografía de Lepidópteros mariposas, 35. Mariposa Caligo spp, ojo de búho, subfamilia Satyrinae (Nymphalidae) 
La iconografía claramente tipifica a mariposas vinculadas al género Caligo de la subfamilia Satyrinae (Lepidóptera: Nymphalidae) (Figuras 33 - 35). Esta especie se caracteriza por presentar colores oscuros y manchas ocelares sobre las alas en vista ventral, denominados ocelos o falsos, ojos que crean un falso rostro con la finalidad de ser usados como defensa. Así mismo, ayuda a desviar el ataque de aves y otros vertebrados (Carter, 1992).

La característica resaltante es las antenas en forma de masa (engrosada en un extremo), el cual es una característica de las mariposas diurnas. Su alimentación es generalmente frutas en descomposición y se encuentran en los valles andinos, especialmente Machupicchu.

\section{LEPIDÓPTERA}

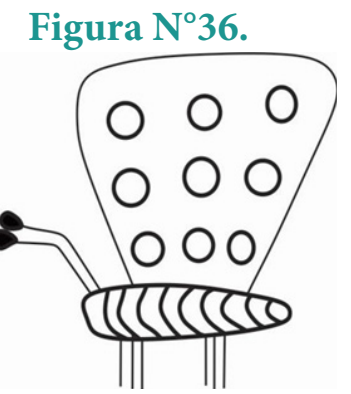

Figura $\mathrm{N}^{\circ} 38$.
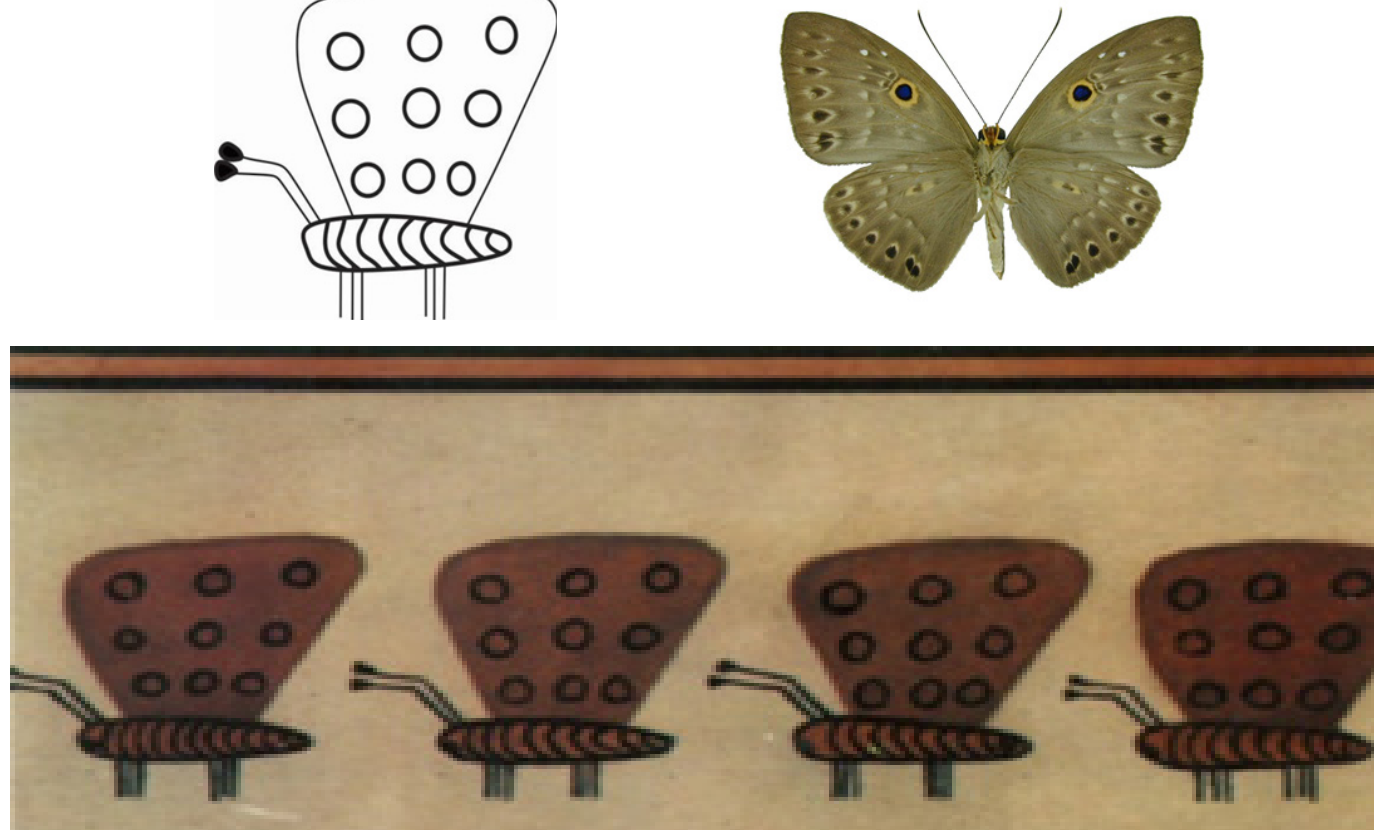

Figura $\mathrm{N}^{\circ} 37$.

36-37. Estilización iconografía de una mariposa diurna, 38. Eurybia spp (Lepidóptera: Riodinidae)

La iconografía muestra a una mariposa diurna posiblemente del género Eurybia (Lepidóptera: Riodinidae) (Figura 36 - 38). Este género se caracteriza por ser de tamaño mediano y pequeño, el cuerpo presenta un tórax corto, abdomen de similar tamaño, primer par de patas reducido y alas dorsalmente con una coloración café, exhibiendo un ocelo en el ala anterior. Este grupo de mariposas pueden ser distinguidas por su hábito de posar bajo las hojas con sus alas abiertas.

Generalmente se encuentran en áreas boscosas húmedas y sombreadas. Además, su alimentación consta de néctar de flores. Estos insectos fueron importantes desde épocas antiguas, relacionados a la resurrección debido a su metamorfosis o tres estados (oruga, crisálida y mariposa), símbolo de la vida, muerte y resurrección. Incluso en la ideología inca fueron relacionados con el Hanan Pacha o mundo de arriba. 


\section{LEPIDÓPTERA}
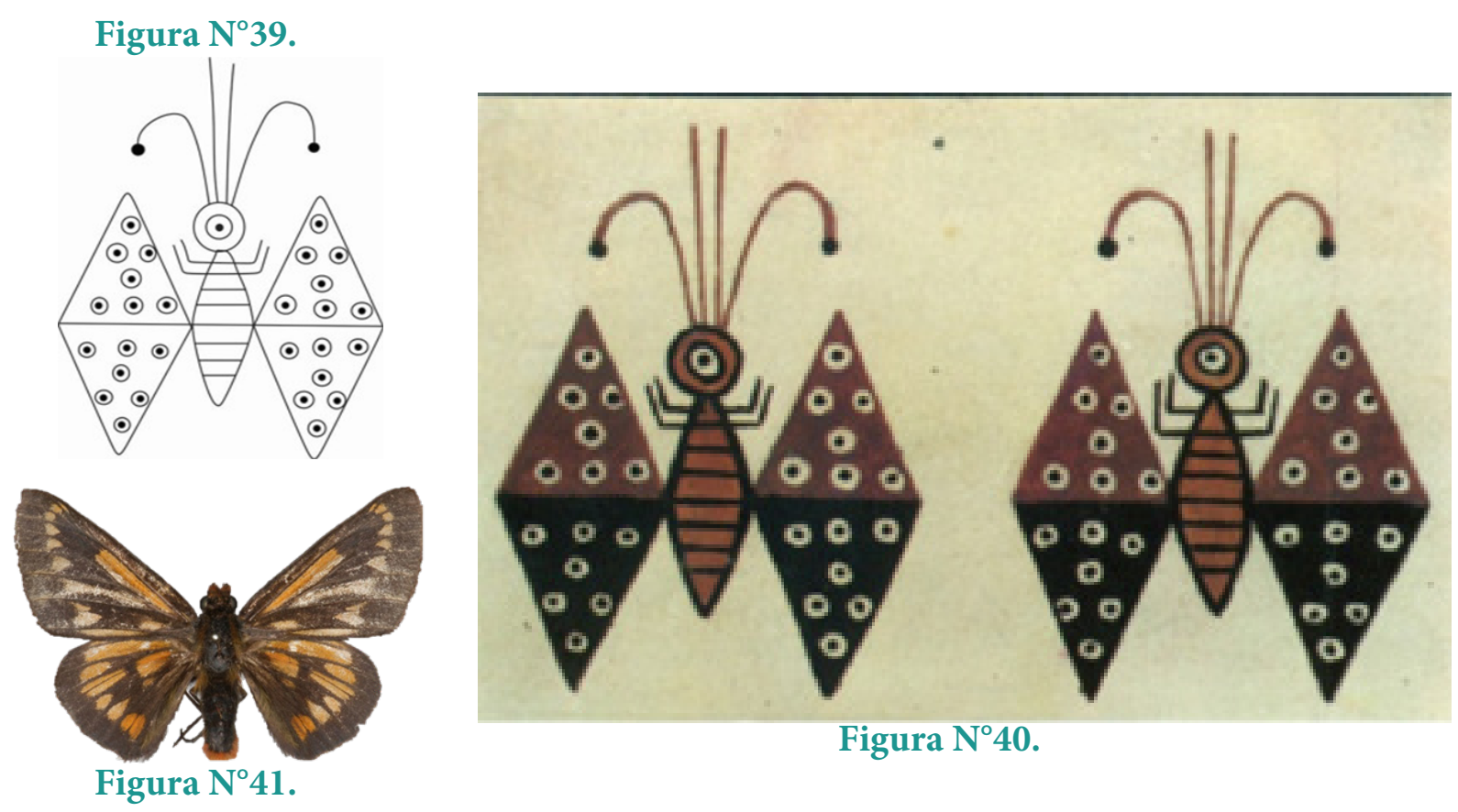

Figura $\mathrm{N}^{\circ} 40$.

Esta iconografía representa posiblemente a lepidópteros del género Metardaris o Hylephila (Figura 39 - 41), pertenecientes a la familia Hesperiidae, pues presenta un cuerpo robusto que caracteriza a este grupo. Este insecto, en el estadio de crisálida o pupa, conocidas tradicionalmente como "huaytampu", fue probablemente consumida desde épocas Prehispánicas debido a su alto contenido en proteínas y grasas naturales. Hoy en día, aún se les puede apreciar expendidas en los mercados tradicionales de Cusco. Este grupo de lepidópteros habitan en los bosques interandinos donde es frecuente la presencia de "chachacomo" Escallonia resinosa (Ruiz \& Pav.) Pers. (Escalloniaceae) que constituye su principal hospedero y son muy comunes en la región andino - montañoso.

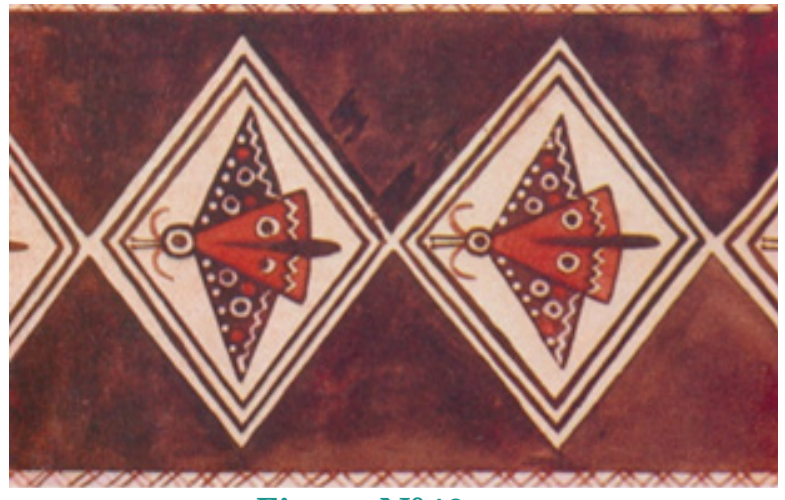

Figura $\mathbf{N}^{\circ} 42$.

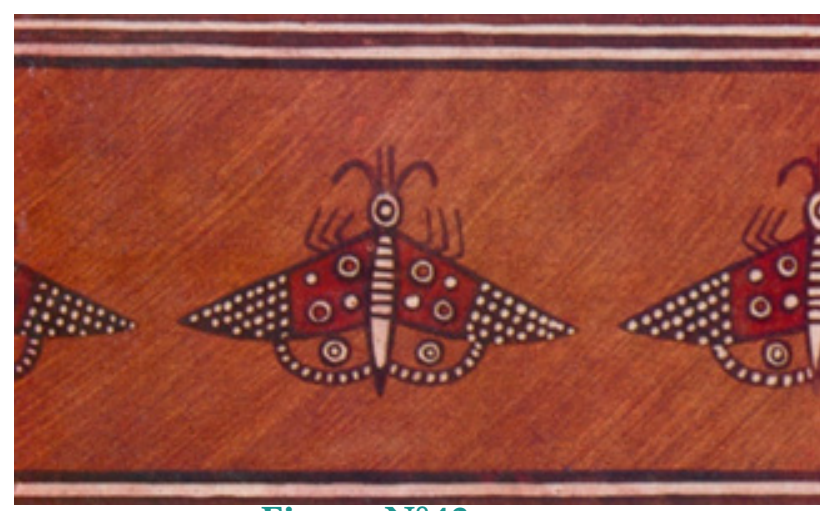

Figura $\mathbf{N}^{\circ} 43$.

Este grupo de Lepidópteros, posiblemente representaría a mariposas del género Vanessa, perteneciente a la familia Nymphalidae (Figura 42) y (Figura43). Es una mariposa de tamaño mediano. Presenta la antena capitada. Son de color anaranjado-parduzca con manchas irregulares negras y en el área apical del ala anterior posee unas manchas blancas. Se caracteriza por su vuelo a baja altura en ambientes abiertos y soleados en general, donde exista el estrato herbáceo como pastizales, cultivos, suburbios, y jardines urbanos. Esta especie abarca un área endémica sudamericana. Comprende zonas tropicales, subtropicales y templadas (Contreras Chialchia \& Contreras Roqué, 2010). 


\section{LEPIDÓPTERA}

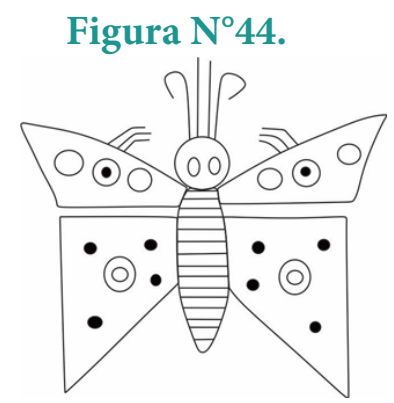

Figura $\mathrm{N}^{\circ} 45$.
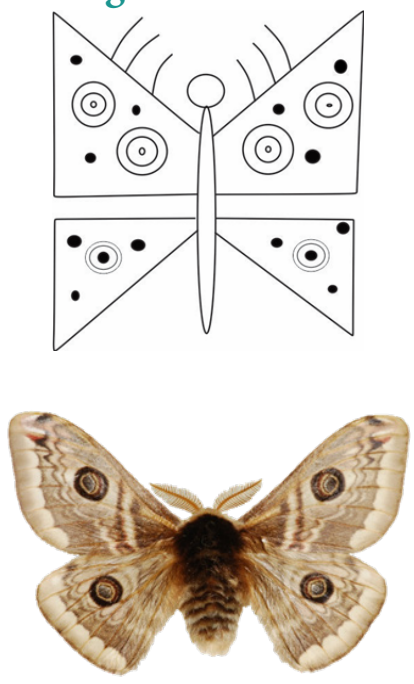

Figura $\mathbf{N}^{\circ} 47$.
Figura $N^{\circ} 46 a$.
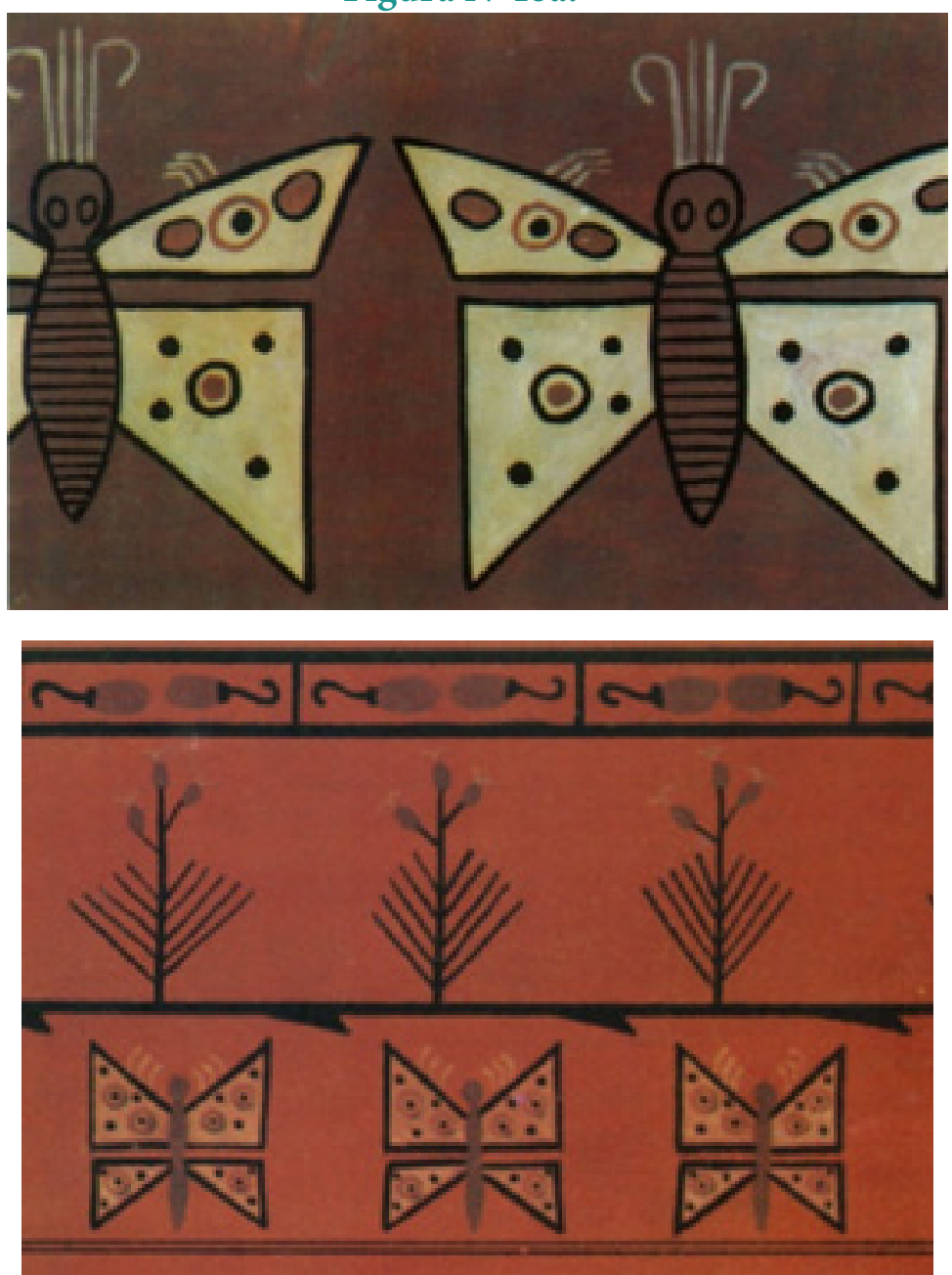

Figura $\mathrm{N}^{\circ} 46 \mathrm{~b}$.

La iconografía, probablemente represente la familia Saturniidae. Es un grupo de mariposas nocturnas que se caracterizan por su comportamiento (hábito de vuelo) y morfología. Presentan un abdomen relativamente pequeño con respecto al tamaño de las alas, las antenas son plumosas o en forma de filamento.

En la lámina 19b es importante citar la representación iconografía de Capsicum spp. "ají" y plantas, probablemente representantes de la familia Bromeliaceae, género Tillandsia, conocidas como achupallas, la cuales presentan los estambres excertos y la ramificación en espiga del escapo florífero. 


\section{LEPIDÓPTERA}

Figura $\mathrm{N}^{\circ} 48$.
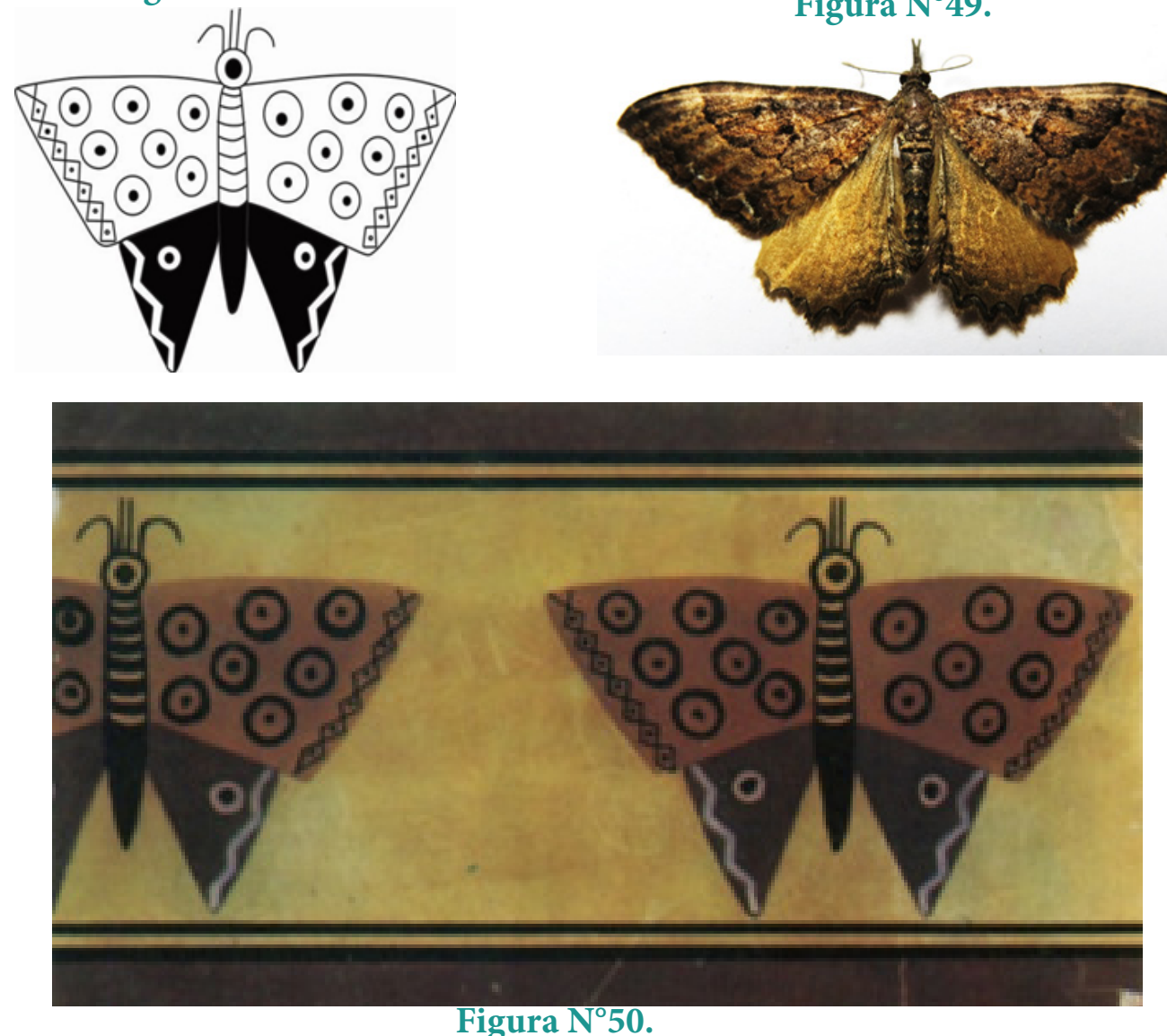

Figura $\mathbf{N}^{\circ} 50$.

Figura $\mathbf{N}^{\circ} 49$.

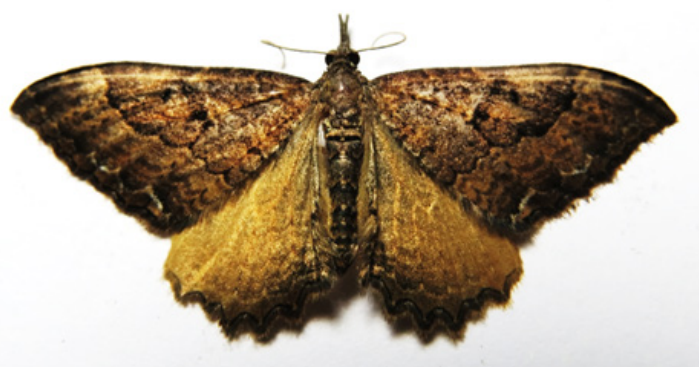

Esta mariposa representada en la iconografía, probablemente represente a la familia Noctuidae, comúnmente llamados polillas, las cuales tienen actividad en horas de la noche. Son de tamaño medio, de abdomen delgado. Se caracterizan por presentar antenas filiformes que, a diferencia de las mariposas diurnas, carecen del ensanchamiento en la parte distal de la antena. Las alas anteriores son de forma triangular y colores poco vistosos.

Las alas posteriores son por lo general más claras e uniformes. Dichas características identifica al grupo de las polillas, llamadas tradicionalmente como "th'uta" y algunas son perjudiciales al cultivo de tubérculos como la papa y granos como el "maíz", principalmente.

Una especie de ave insectívora Troglodytes aedon (Troglodytidae) se alimenta de estos lepidópteros, constituyéndose como un controlador natural. De ahí su nombre de th'utapallana, traducido en el idioma español como recogedor de polillas (Figuras 48 - 50). 


\section{LEPIDÓPTERA}

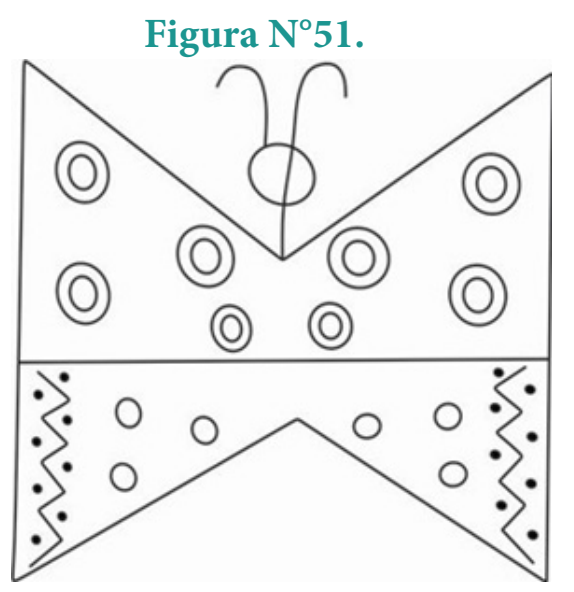

Figura $N^{\circ} 52$.

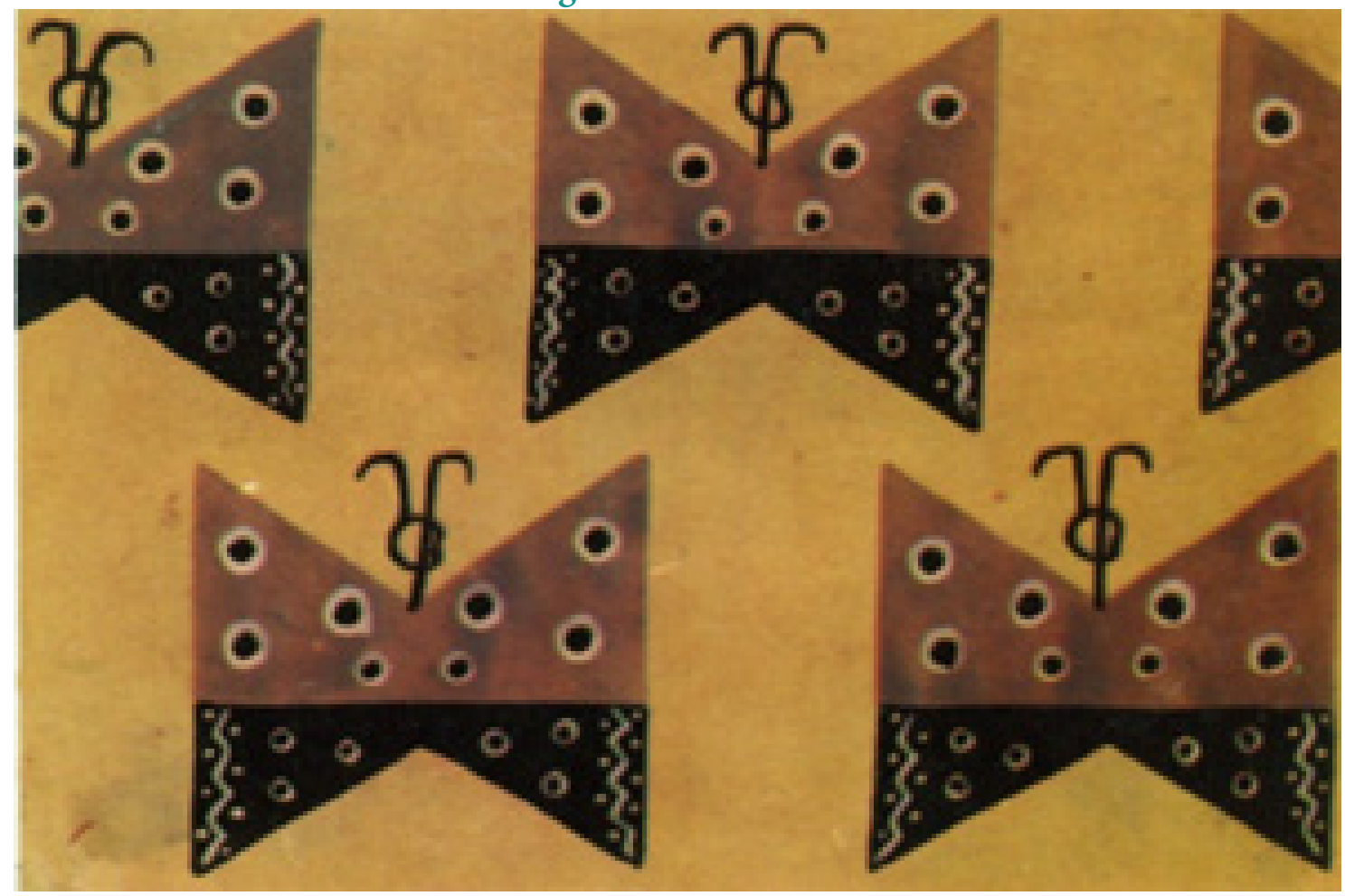

La iconografía representa al grupo de lepidópteros de vista dorsal que posiblemente sea de hábito nocturno, debido a que se le observa una característica muy importante, que es la presencia de antenas simples (filiformes), las cuales cumplen funciones importantes como olfato y tacto. Así mismo, en la lámina se puede apreciar representaciones estilizadas de círculos en ambas alas.

La belleza de las mariposas ha significado desde la antigüedad un símbolo estético y de inspiración para la decoración de diversos objetos y obras. Sin embargo, en la cultura andina las mariposas nocturnas fueron símbolo de mal augurio o anuncio de muerte. Por ejemplo, existe la leyenda que relaciona a este insecto con la epidemia que diezmaría al ejercito del inca y que causaría la muerte del propio Hayna Capac (Taira, 2015) (Figuras 51,52). 


\section{LEPIDÓPTERA}
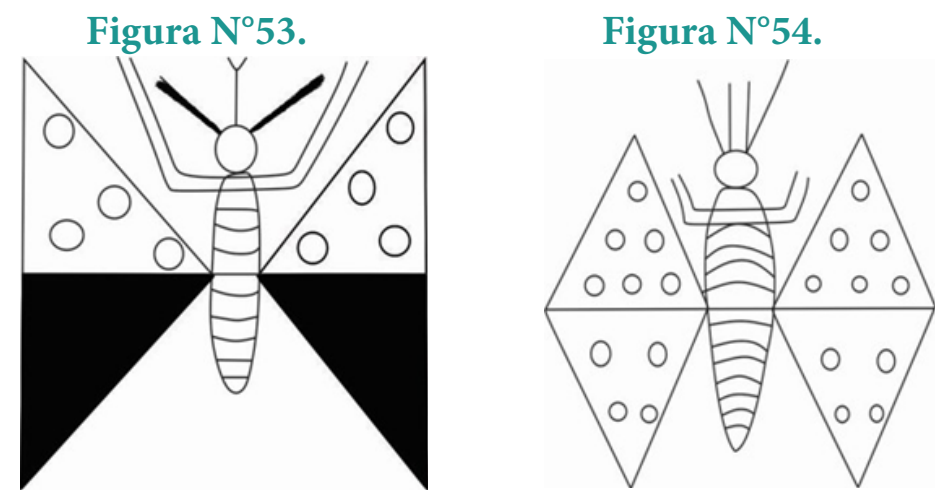

Figura $N^{\circ} 56$.

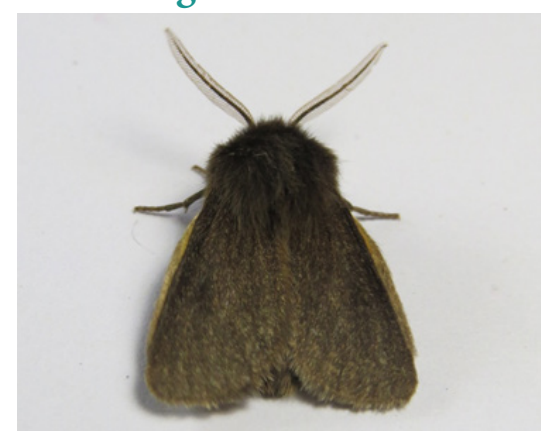

Figura $N^{\circ} 55 a$.

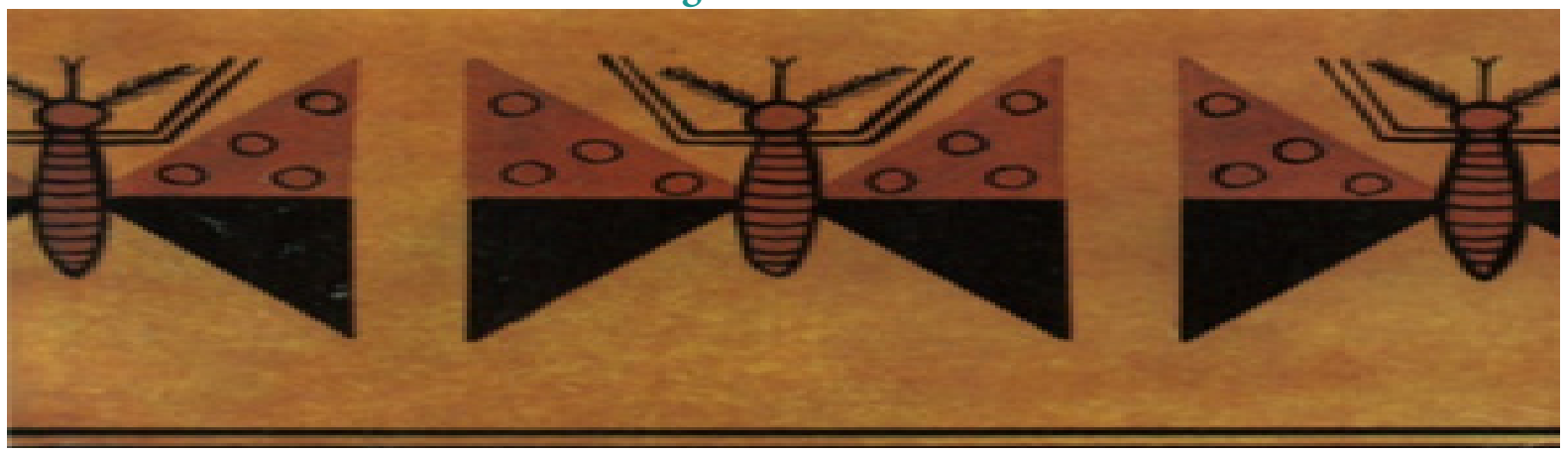

Figura $\mathrm{N}^{\circ} 55 \mathrm{~b}$.

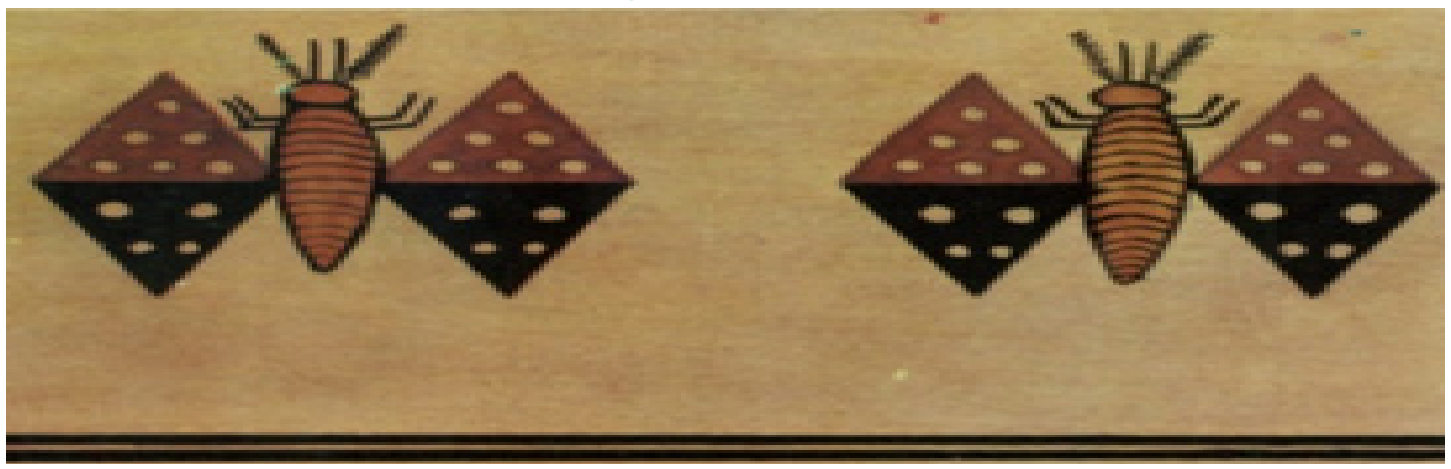

En estas representaciones de lepidopteros (Figuras 53 - 56 láminas 22a y 22b), destaca el detalle de las antenas plumosas y el cuerpo robusto. Por lo tanto, la iconografía posiblemente represente a la familia Lasiocampidae. Son de hábitos nocturnos. Durante el reposo, sus alas se pliegan sobre el dorso.

Esta familia se caracteriza por ser de tamaño mediano, de colores grises o pardas, poseer una abundante pubescencia que les proporciona abrigo debido a la falta de luz solar. Y sobre todo presentar antenas bipectinadas que les permite captar olores, sonidos y vibraciones. Además, les permite percibir el olor de las hembras en época de celo. 


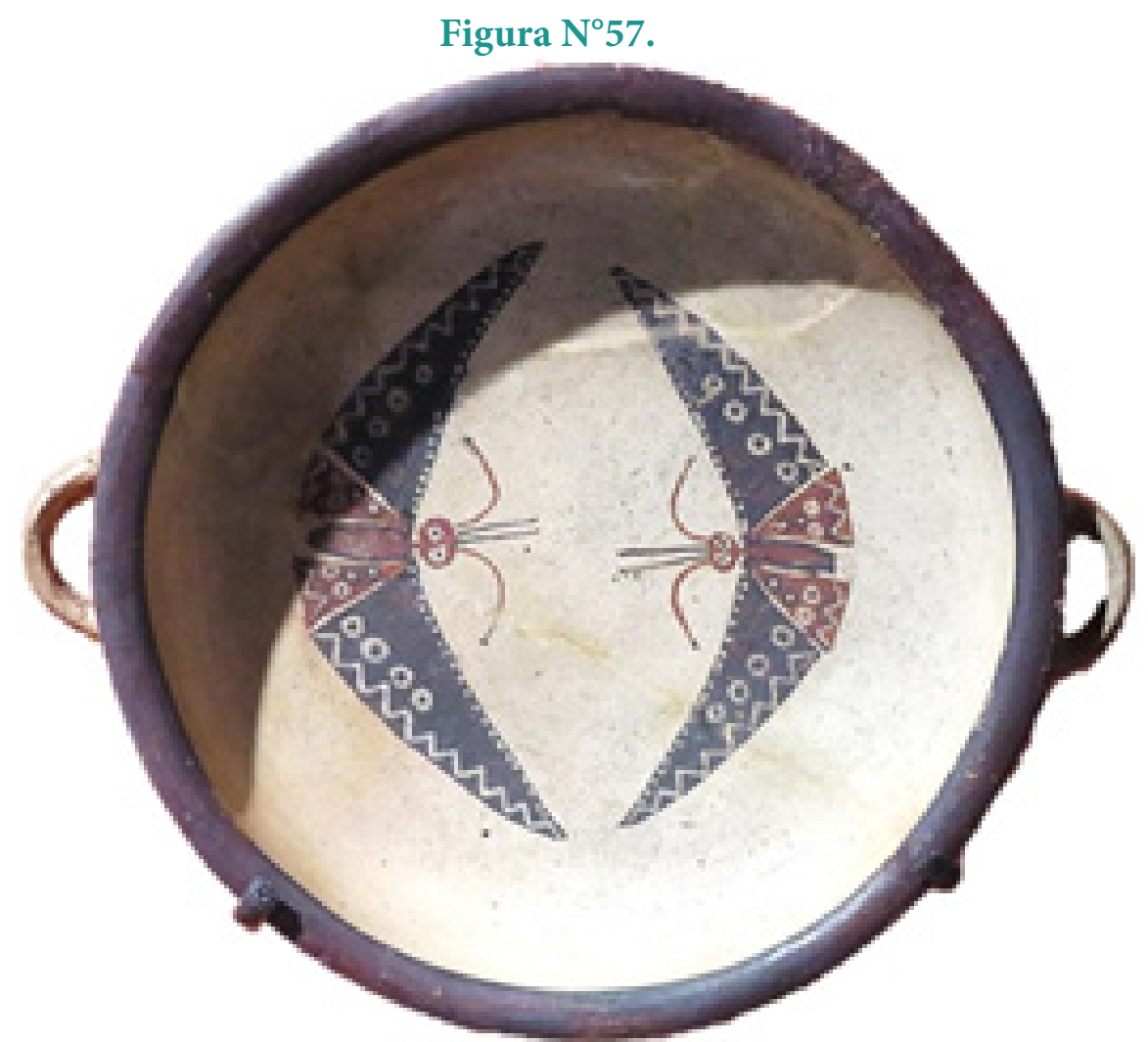

Plato blanco decorado con mariposas en el interior. Posiblemente importado del área del Lago Titicaca. Cueva 37. Machu Picchu. Altura: $2.5 \mathrm{~cm}$., diámetro del borde $12.3 \mathrm{~cm}$, diámetro máx. $14.5 \mathrm{~cm}$. (Museo Casa Concha DDC - Cusco). Foto: E. Suclli 2019

La Figura 57 representa a uno de los platos pequeños exibidos en el museo de la Casa Concha en la ciudad del Cusco (dos únicos platos). En referencia a estos platos inka, se recoje la informacion de dos investigadores. El Dr. Gerardo Lamas menciona que "la primera representacion conocida de una especie de Lepidóptero de Machupicchu, ésta fue elaborada siglos antes de que Bingham visitara el área, como quedó demostrado por la figuras estilizadas de la faz superior de dos ejemplares pintados sobre un plato incaico, hallado por la expedición de Bingham en una cueva de Machupicchu (Bingham 1915). Esta figuras fueron usadas posteriormente en el logotipo del segundo Simposio sobre Lepidópteros Neotropicales, desarrollado en 1983 en Arequipa, Perú (Lamas 1985). Se presume que tales figuras corresponderían a una especie de mariposa nocturna, posiblemente del género Euryglottis (Sphingidae). Aunque varios Euryglottis ocurren en Machupicchu, ninguna especie conocida muestra los prominentes círculos exhibidos en las alas anteriores y posteriores de los especímenes figurados, que podrian haber ser añadidos por el artista con fines puramente decorativo". . (Las Mariposas de Machu Picchu. PROFONANPE 2004).

Del mismo modo el Ing. Wylli Vargas, refiere que las figuras estilizadas "Corresponden indudablemente a un Lepidóptero. Presenta la cabeza bien diferenciada portando un par de ojos, un par de antenas, los palpos labiales bien desarrollados o quizá la espirotrompa extendida con las gáleas separadas. El primer par de alas muy desarrollado y el según par pequeño, asentadas hacia la parte anterior de lo que correspondería al toráx, llevan diseños circulares y de líneas quebradas hacia el borde externo; se aprecia tambíen la parte abdominal. Posiblemente se trate de un lepidóptero del género Thysania. Corresponde a una de las dos figuras que se encuentran en la cara interna de una fuente o plato Inca, 
ambas de las mismas características y en posición opuesta. (Insectos en la Iconografia Inka. Revista Peruana de Entomología 1995)

Los dos autores, indudablemente hacen referencia a Lepidópteros, pero cada uno identifica dos taxas diferentes: Euryglottis y Thysania. En la actualidad, estos dos géneros taxonómicos se presentan para la entomofauna de Machu Picchu y corresponden a un grupo de mariposas nocturnas llamadas Noctuidos. En nuestro medio, estas son conocidas como taparacos, cuya presencia está asociada con hechos de infortunio para el hogar.

La asociación entre insectos y cultivos, representada en iconografia inka, estableció sinergias que a manera de un lenguaje abstracto y simbólico, expresan esta relación, principalmente vinculada con la cadena productiva agrícola de los cultivos de "maíz" y “ají". Este último, al parecer fue casi siempre un acompañante del maíz. En cuanto a esto, Perry et al. (2007: 125) menciona que cada vez que se hallaba maíz, en algun sitio prehispánico de las Américas, este suele estar asociado a restos de ají, y que desde que la poblaciones prehispánicas lo incorporaron en sus dietas, nunca más lo dejaron de consumir. Actualmente, en el ambito peruano se conocen 25 especies de ajíes silvestres y 5 domesticadas.

La iconografia analizada reporta la posible asociacion de "ajíes" Capsicum spp., Capsicum sinense Jacq. (Solanaceae) y el "maíz" Zea mays L. (Poaceae) con insectos. En general, al realizarse la aproximacion taxonómica se reconocen 21 tipos de insectos, de los cuales 7 estarían asociados a estos cultivos. La asociacion representaría una forma de percepción y la abstracción de la convivencia humana con estos insectos, la presion que ejercen estos en el cultivo, ya sea en la forma de plagas dañinas o como controladores biológicos naturales; sin olvidar el hecho de que muchas especies están asociadas a los procesos de polinización y dispersión de vegetales. 